\title{
Chapter 4 \\ Capillary (Gel) Electrophoresis-Based \\ Methods for Immunoglobulin \\ (G) Glycosylation Analysis
}

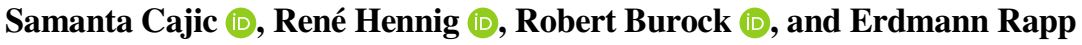

\section{Contents}

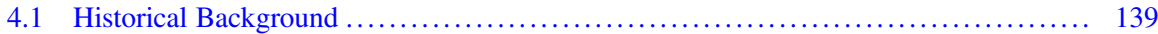

4.2 Background: Principles of Capillary (Gel) Electrophoresis $(\mathrm{C}(\mathrm{G}) \mathrm{E}) \ldots \ldots \ldots \ldots \ldots \ldots \ldots \ldots$

4.3 Performance, Benefits, and Potentials of Capillary (Gel) Electrophoresis C(G)E ..... 142

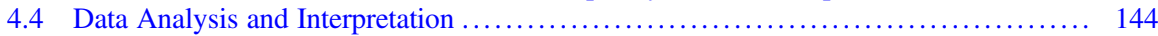

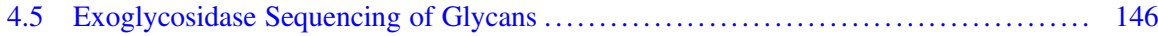

4.6 Coupling Capillary Electrophoresis with Mass Spectrometry .................... 149

4.7 Latest Developments: Miniaturization of CE Systems-Microchip CE ............. 150

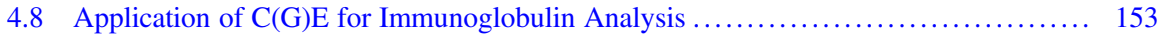

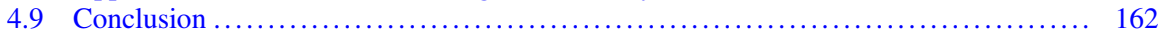

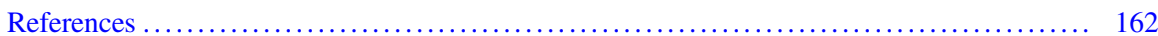

\begin{abstract}
The in-depth characterization of protein glycosylation has become indispensable in many research fields and in the biopharmaceutical industry. Especially knowledge about modulations in immunoglobulin $\mathrm{G}(\mathrm{IgG}) \mathrm{N}$-glycosylation and their effect on immunity enabled a better understanding of human diseases and the development of new, more effective drugs for their treatment. This chapter provides a deeper insight into capillary (gel) electrophoresis-based $(\mathrm{C}(\mathrm{G}) \mathrm{E})$ glycan analysis, addressing its impressive performance and possibilities, its great potential regarding
\end{abstract}

Samanta Cajic and René Hennig contributed equally.

The original version of this chapter was revised: Figures 4.1, 4.2, 4.3 and 4.6 have been updated. The correction to this chapter can be found at https://doi.org/10.1007/978-3-030-76912-3_19

S. Cajic

Max Planck Institute for Dynamics of Complex Technical Systems, Magdeburg, Germany

R. Hennig $(\bowtie) \cdot$ E. Rapp

Max Planck Institute for Dynamics of Complex Technical Systems, Magdeburg, Germany

glyXera GmbH, Magdeburg, Germany

e-mail: r.hennig@glyxera.com

R. Burock

glyXera GmbH, Magdeburg, Germany 
real high-throughput for large cohort studies, as well as its challenges and limitations. We focus on the latest developments with respect to miniaturization and mass spectrometry coupling, as well as data analysis and interpretation. The use of exoglycosidase sequencing in combination with current $\mathrm{C}(\mathrm{G}) \mathrm{E}$ technology is discussed, highlighting possible difficulties and pitfalls. The application section describes the detailed characterization of $N$-glycosylation, utilizing multiplexed CGE with laser-induced fluorescence detection (xCGE-LIF). Besides a comprehensive overview on antibody glycosylation by comparing species-specific IgGs and human immunoglobulins A, D, E, G, and M, the chapter comprises a comparison of therapeutic monoclonal antibodies from different production cell lines, as well as a detailed characterization of Fab and Fc glycosylation. These examples illustrate the full potential of $\mathrm{C}(\mathrm{G}) \mathrm{E}$, resolving the smallest differences in sugar composition and structure.

Keywords Capillary gel electrophoresis $\cdot N$-glycosylation $\cdot$ Biopharmaceuticals Immunoglobulin $\cdot \operatorname{IgA} \cdot \operatorname{IgD} \cdot \operatorname{IgE} \cdot \operatorname{IgG} \cdot \operatorname{IgM} \cdot$ Monoclonal antibody $\cdot \mathrm{mAb} \cdot \mathrm{APTS} \cdot$ xCGE-LIF $\cdot$ CE-MS $\cdot$ Chip-CE $\cdot$ Exoglycosidase

\section{Abbreviations}

$\begin{array}{ll}\text { APTS } & \text { 8-aminopyrene-1,3,6-trisulfonic-acid } \\ \text { CE } & \text { Capillary electrophoresis } \\ \text { CGE } & \text { Capillary gel electrophoresis } \\ \text { CHO } & \text { Chinese hamster ovary } \\ \text { CQA } & \text { Critical quality attribute } \\ \text { CZE } & \text { Capillary zone electrophoresis } \\ \text { DB } & \text { Database } \\ \text { EOF } & \text { Electroosmotic flow } \\ \text { ESI } & \text { Electrospray ionization } \\ \text { Fab } & \text { Fragment antigen binding } \\ \text { Fc } & \text { Fragment crystallizable } \\ \text { Fuc } & \text { Fucose } \\ \text { Gal } & \text { Galactose } \\ \text { GlcNAc } & \text { N-acetylglucosamine } \\ \text { GU } & \text { Glucose units } \\ \text { HAGR } & \text { Hepatic asialo-glycoprotein receptor } \\ \text { HILIC } & \text { Hydrophilic interaction liquid chromatography } \\ \text { HMOS } & \text { Human milk oligosaccharides } \\ \text { HPLC } & \text { High-performance liquid chromatography } \\ \text { Ig } & \text { Immunoglobulin } \\ \text { LIF } & \text { Laser-induced fluorescence detection } \\ \text { mAb } & \text { Monoclonal antibody } \\ \text { MALDI-TOF-MS } & \text { Matrix-assisted laser desorption ionization with time-of- } \\ & \text { flight MS }\end{array}$




$\begin{array}{ll}\text { Man } & \text { Mannose } \\ \text { MS } & \text { Mass spectrometry } \\ \text { MS/MS } & \text { Tandem mass spectrometry } \\ \text { MTU } & \text { Migration time unit } \\ \text { MTU" } & \text { Double aligned migration time units } \\ \text { Neu5Ac } & N \text {-acetyl-neuraminic acid } \\ \text { Neu5Gc } & N \text {-glycolyl-neuraminic acid } \\ \text { NMR } & \text { Nuclear magnetic resonance } \\ \text { Sia } & \text { Sialic acid } \\ \text { SNFG } & \text { Symbol nomenclature for glycans } \\ \text { UPLC } & \text { Ultra-performance liquid chromatography } \\ \text { xCGE-LIF } & \text { Multiplexed capillary gel electrophoresis with laser-induced } \\ & \text { fluorescence detection }\end{array}$

\subsection{Historical Background}

Electrophoresis was born more than 200 years ago (Ruess 1809), even long before the concept of chromatography was described. However, it took about 150 more years before the use of capillaries was introduced (Hjertén 1967). From the late 1960s, it took an additional decade to establish capillary electrophoresis $(C E)$ as it is most widely known today, enabling separations that seemed unattainable at that time (Jorgenson and DeArman Lukacs 1981; Jorgenson and Lukacs 1981a, b). The increased efficiency and the amazing separation capabilities together with short analysis times, induced a growing interest among the scientific community. Since then, CE has constantly been improved and has become an important tool in the analysis of a wide class of compounds, from small ions over amino acids and peptides/proteins to large DNA fragments (Saraswathy and Ramalingam 2011). However, the employment of CE for glycan analysis lagged behind other commonly used analytical techniques. Attempts to use CE for glycan analysis started in the 1990s, but they were rather humble and not broadly embraced-neither by the glycoscientific community nor by industrial laboratories. Today, 40 years since the potential of CE was recognized, the advantages of the method for analysis of glycans are becoming increasingly obvious and appreciated. Ready-to-use CE methods and kits on the market (glyXera 2020; Thermo Fisher Scientific 2018; Ludger 2018; ProZyme 2018; SCIEX 2018; PerkinElmer 2018) enable fast and robust comparison of glycan profiles, which makes the technology more routine in academic research and industry. In the following sections, we will emphasize some of the reasons why $\mathrm{CE}$ is gaining popularity and underline why this technology is attractive for the biopharmaceutical industry, especially regarding the analysis of immunoglobulin (Ig) glycosylation. Additionally, some current and future challenges, as well as possible future methodological developments, will be addressed. 


\subsection{Background: Principles of Capillary (Gel) Electrophoresis $(\mathbf{C}(\mathbf{G}) \mathbf{E})$}

Capillary electrophoresis is the umbrella term for various capillary electrophoretic separation techniques and methods, such as capillary zone electrophoresis $(C Z E)$ and capillary gel electrophoresis $(C G E)$. The differential migration of charged molecular species (ions) in a narrow capillary $(25-75 \mu \mathrm{m})$ containing an electrolyte solution under the influence of high voltage (usually $10-30 \mathrm{kV}$, generating an electric field) is the basis for separation by CE (Watson 2012). An analyte is attracted to either the anode (positive electrode) or the cathode (negative electrode), and its movement (electrophoretic mobility) in an electric field results from both electrical and frictional force contributions. The movement of a charged analyte through a conductive solution is dependent on the charge of the analyte and the magnitude of the applied electric field. Additionally, a frictional force will impede the movement induced by the electrical field to a certain extent, dependent on the viscosity of the electrolyte solution and the analyte radius/molecular size or shape. Thus, the mobility and, therefore, the separation is based on the size-to-charge ratio of the analytes. Besides electrophoretic velocity, electroosmotic flow $(E O F)$ is influencing the movement of the analyte through the capillary. EOF is the bulk liquid motion in a capillary when a high voltage (electric field) is applied. In a capillary composed of fused silica, the surface possesses negative charges $\left(\mathrm{SiO}^{-}\right)$over a wide $\mathrm{pH}$ range $(\mathrm{pH} 4-12)$. This negatively charged surface attracts positively charged electrolytes from the running buffer. Along an electric field, these cations (enriched at the capillary wall) move towards the cathode. Due to solvation and liquid viscosity, these cations drag the surrounded bulk solvent with them along the capillary axis, creating a net flow toward the cathode, the EOF. Thus, all analytes, irrespective of their charge, are pushed in one direction, enabling simultaneous separation and detection of cationic $(\mathrm{EOF}+$ ion migration $=$ fastest $)$, neutral $(\mathrm{EOF}=$ middle $)$ and anionic $(\mathrm{EOF}-$ ion migration $=$ slowest) analytes (Holland et al. 1997). Although this is rather a rough summary of the separation mechanism, the reader should recognize that the parameters involved in optimizing the technique to produce separation are very complex. However, the effort pays off as very small changes in molecular structure can lead to quite marked differences in migration if variables are carefully balanced. There is a large volume of literature regarding $\mathrm{CE}$ separations of glycans exploiting a variety of possible setups, methods, modes, and parameters (e.g., capillary material, dimensions, and surface coating, voltage, current, polarity, temperature, buffer type and concentration, $\mathrm{pH}$, additives/modifiers, injection technique, detection mode, etc.) that is beyond the scope of this review (Campa and Rossi 2008; Ruhaak et al. 2010a; $\mathrm{Lu}$ et al. 2018). However, due to a boom of applications in the field of glycan analysis and particular interest in the biopharmaceutical industry, one technique deserves to be further dissected-capillary gel electrophoresis (CGE).

After providing the complete genetic blueprint of human life (Collins et al. 2004), CGE-based Genetic Analyzers (DNA analyzers) found their application in the field of glycan analysis, with a more complex challenge but a new hope of deciphering the 
glycome (Schwarzer et al. 2008; Laroy et al. 2006; Callewaert et al. 2001; Ruhaak et al. 2010b). These instruments combine four great advantageous features, which make them very powerful analytical tools in glycoscience. First, in CGE, the abovementioned EOF is typically completely suppressed by employing a neutral capillary (permanently or dynamically coated) filled with a gel mesh polymer. The use of such a gel buffer increases the viscosity of the electrophoresis medium. Consequently, due to the role of viscosity in frictional drag, this increases the time analytes spend in the capillary (decrease of electrophoretic mobility), while decreasing diffusion and thereby improving the separation (Watson 2012; Guttman et al. 1994; Luo et al. 2010). Thanks to this first advantageous feature, glycans are separated based on mass-to-charge ratio and molecular size/shape (hydrodynamic volumes) with high resolution (Guttman et al. 1996a; Guttman and Herrick 1996). Second, the large surface-to-volume ratio of narrow capillaries enables a very good heat transfer. This in turn raises the possibility to apply very high electric fields, which increases the electrophoretic mobility and consequently decreases the analysis time. Third, besides its high separation efficiency in a short time, this method is also attractive due to the possibility to employ laser-induced fluorescence $(L I F)$ detection, known for its impressive sensitivity (low attomole range) (Guttman 1996; Hennig et al. 2011a). The fourth advantage is the possibility to employ a multi-capillary format (multiplexing), incorporating up to 96 capillaries in parallel, so that hundreds of samples can be measured by CGE per day (Mittermayr et al. 2013). As a result, modern multiplexed capillary gel electrophoresis with laser-induced fluorescence detection $(x C G E-L I F)$ instruments offer an amazing high-throughput, separation performance and sensitivity. Another attractive option provided, e.g., by Applied Biosystems Genetic Analyzers, is a recording of up to six different fluorescent dyes (in six independent detection traces/channels) simultaneously within one run (all excited by only one laser). As described later, this special feature has been exploited for internal alignment of migration times (glycans and internal base pair standard labeled with different dyes), giving long-time stable migration times (Callewaert et al. 2001; Laroy et al. 2006; Schwarzer et al. 2008; Reusch et al. 2014). The basic setup of a Genetic Analyzer ((x)CGE-LIF system) and the principle of glycan separation is depicted in Fig. 4.1.

The majority of glycans are uncharged and therefore would neither be electrokinetically injected nor migrate in an electric field when EOF is suppressed. Additionally, glycans lack a chromophore/fluorophore necessary for optical detection (Guttman et al. 1996b). Thus, an ideal label for C(G)E-LIF needs to have high fluorescent yield, carry (sufficient) negative charges stable over a broad $\mathrm{pH}$ range (for electric field-mediated mobilization), and it needs to have an excitation wavelength corresponding to the output wavelength of commercially available lasers (commonly argon-ion laser) (Briggs et al. 2009). All these requirements are met in 8-aminopyrene-1,3,6-trisulfonic-acid (APTS) fluorescent dye (Evangelista et al. 1995; Ruhaak et al. 2010b), which is almost universally employed in CE-based glycan analysis today. High absorptivity and quantum yield of APTS enable a highly sensitive LIF detection, thus making CE an appropriate method for high-sensitivity glycan analysis, even with low sample amounts (Guttman et al. 1996a). 

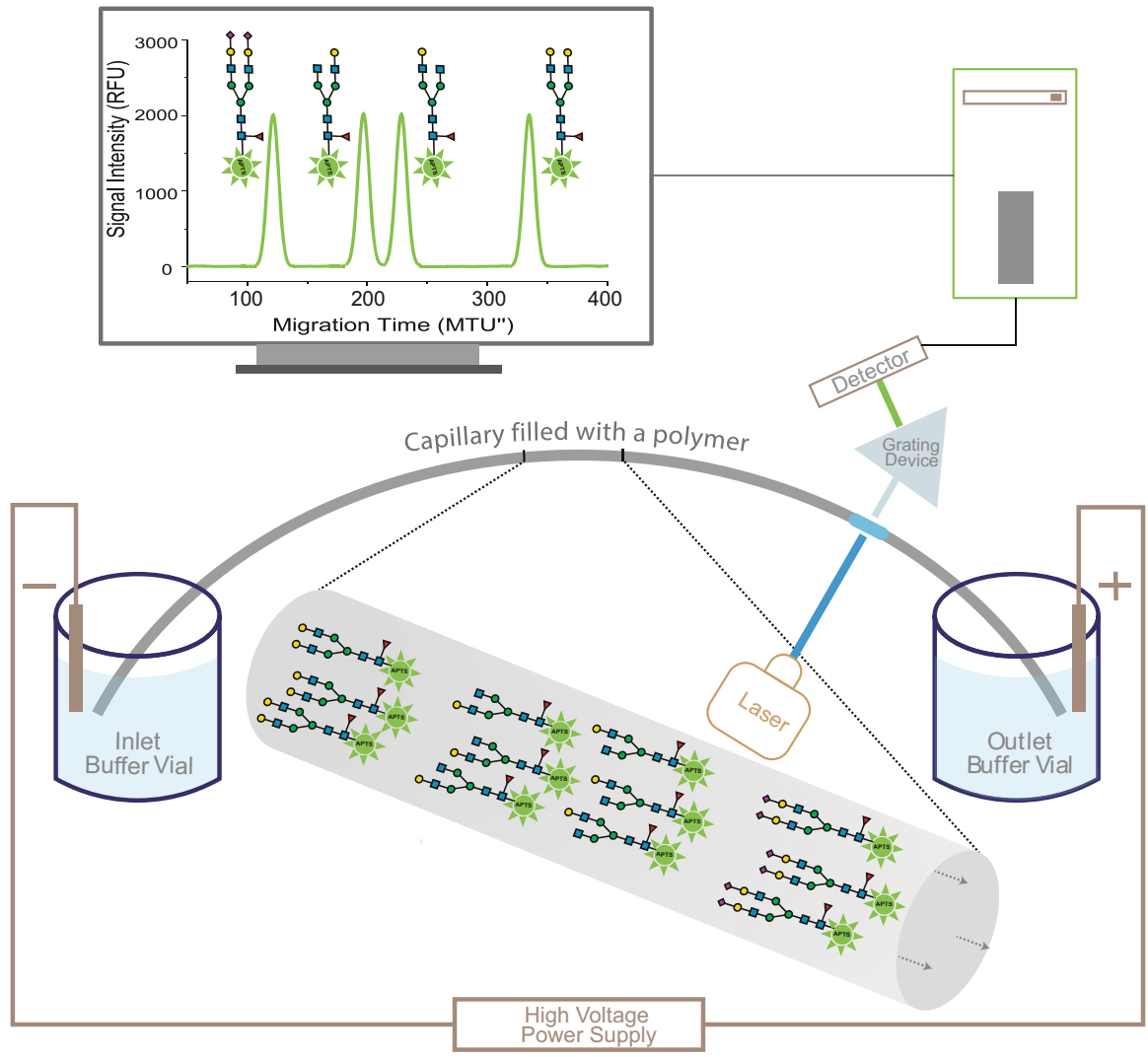

Fig. 4.1 Common separation of glycans utilizing an xCGE-LIF-based DNA sequencing system. High injection voltage is applied for a brief period, causing sample (glycans labeled with a negatively charged fluorescent dye, e.g., APTS) to enter the inlet of the gel-filled capillary by electromigration (electrokinetic injection). The electric field is applied under reverse polarity (cathode at injection and anode on the detection side) so that anions (i.e., negatively charged labeled glycans) migrate towards the detection window. As demonstrated, fluorescently labeled glycans are separated, based not only on the differences in their mass-to-charge ratios but also on their hydrodynamic volumes. Although sequencing systems benefit from multi-capillary format, only one capillary is presented here for simplicity. The $\mathrm{x}$-axis of the schematic electropherogram is given in double aligned migration time units $\left(\mathrm{MTU}^{\prime \prime}\right)$. The signal intensity of the $\mathrm{y}$-axis is given in relative fluorescent units (RFU). Symbolic representation of $N$-glycan structures follows the guidelines of Symbol Nomenclature for Glycans (SNFG) (Varki et al. 2015)

\subsection{Performance, Benefits, and Potentials of Capillary (Gel) Electrophoresis $\mathbf{C}(\mathbf{G}) \mathbf{E}$}

CE provides remarkable separation efficiencies and resolution in a very short time, which makes this technology appealing for the analysis of structurally complex and diverse molecules like glycans. Recent work has shown that CE can separate even 
challenging positional and linkage isomers in one single analysis run. For example, the method is capable of distinguishing even carbohydrate position in a glycan structure [e.g., nonreducing terminal residue on $\alpha 1-3$ arm from terminal residue on $\alpha 1-6$ arm of the core structure (see Fig. 4.2b, c) (Hennig et al. 2016; Schwedler et al. 2014a, b; Chen et al. 2017; Huang et al. 2017; Guttman et al. 2015)], along with position and linkage of fucose (Fuc) [e.g., $\alpha 1-6$ core Fuc from $\alpha 1-3 / 1-4$ Fuc on antenna $N$-acetylglucosamine (GlcNAc) or $\alpha 1-2$ Fuc on galactose (Hennig et al. 2016; Konze et al. 2017; Thiesler et al. 2016; Weiz et al. 2016; Schwedler et al. 2014a)], type and linkage of sialic acids (Sia) [e.g., $\mathrm{N}$-acetylneuraminic acid (Neu5Ac) from $\mathrm{N}$-glycolylneuraminic acid $(\mathrm{Neu} 5 \mathrm{Gc}$ ), see Fig. 4.3d (Abeln et al. 2017), and $\alpha 2-3$ from $\alpha 2-6$ (Hennig et al. 2016; Konze et al. 2017; Thiesler et al. 2016; Donczo et al. 2017; Meininger et al. 2016)], and linkage of galactose (Gal) [e.g., $\beta 1-3 \mathrm{Gal}$ from $\beta 1-4 \mathrm{Gal}$ (Konze et al. 2017; Thiesler et al. 2016; Schwedler et al. 2014a; Muñoz et al. 2019)]. This feature becomes especially advantageous when thinking about the importance of determining immunogenic $\alpha$-Gal and Neu5Gc on glycoprotein therapeutics (Chung et al. 2008; Teranishi et al. 2002; Van der Linden et al. 2000). Additionally, the fact that only $\alpha 2-6$, and not $\alpha 2-3$ sialic acid, affects the anti-inflammatory activity of IgG antibody (Anthony et al. 2008) makes it crucial to have a method capable of their differentiation.

Besides speed, resolution, sensitivity, and simplicity, compatibility with a wide range of samples is one of the biggest advantages of $\mathrm{C}(\mathrm{G}) \mathrm{E}$. Due to the robustness of the method, only a modest sample purification is necessary. Large amounts of cell debris (Konze et al. 2017; Thiesler et al. 2016; Abeln et al. 2017) or other impurities like large excess of fluorescent labeling dye (Croset et al. 2012) will not prevent a successful analysis. For comparison, in LC-based analytics, such cell debris can block the column or at least accumulate inside of it, resulting in a significant decrease of separation power. Consequently, a costly column exchange or a time-consuming column cleaning procedure is needed. In contrast, in CGE, the separation matrix (polymeric gel) is exchanged after each run; thus impure samples are not problematic in terms of clogging or sample carryover. Even sample clean-up after exoglycosidase digest—for LC an obligatory step — can be omitted, further reducing analysis time and workload (Szigeti and Guttman 2017).

Moreover, $\mathrm{CE}$ analysis is beneficial when enormous differences in analyte concentrations are present in one sample. For example, it could be shown by Kottler et al. that lactose, which represents up to $85 \%$ of the free oligosaccharides in human milk, did not interfere with the analysis of other more complex but low abundant human milk oligosaccharides (HMOS) (Coppa et al. 1993). While in xCGE-LIF the lactose peak appears without any peak shape deformation, even when injected in amounts far above the linear detection range, for LC-based methods, lactose needs to be depleted from the milk samples before HMOS analysis to avoid massive peak broadening and tailing as a result of column overload (Kottler et al. 2013). Similar problems might be faced when using mass spectrometry $(M S)$.

After reviewing all the given advantages, an important aspect of the $\mathrm{N}$-glycan analysis is the costs. Resources in academia and industry are often quite limited, especially if hundreds or thousands of samples need to be analyzed in a short time- 
i.e., in real high-throughput. Here glycan analysis by xCGE-LIF, utilizing DNA analyzers originally built for Sanger sequencing, outperforms conventional LC and MS approaches. With low material costs (due to minimal sample preparation) and low operating costs (low maintenance, no organic solvents and solvent disposal costs), the overall cost are significantly lower for xCGE-LIF (Huffman et al. 2014; Mahan et al. 2015) than for LC or LC-MS. Moreover, data analysis and interpretation became user-friendly with available software solutions (see section "Data Analysis and Interpretation"), further reducing expenses for hands-on time and expertise.

Finally, C(G)E-based methods were also successfully applied for the absolute quantification of carbohydrates (Sarkozy et al. 2021; Eussen et al. 2021), which completes the wide field of applications. Taken together, unprecedented separation together with low costs, robustness, speed of analysis, multiplexing capability, high sensitivity, and nano- to femtoliter injection volumes make $\mathrm{CE}$ a veritable competitor to other more traditionally used techniques for glycan analysis.

\subsection{Data Analysis and Interpretation}

One way to obtain structural information and assign glycans to peaks is through co-injection of glycan standards, which are commercially available and fully characterized (Guttman et al. 1996a, b; Guttman and Herrick 1996; Reusch et al. 2014). In a so-called spiking experiment, the glycan is indirectly identified by the height increase of an often perfectly Gaussian-shaped CE peak. Unfortunately, only a very limited number of glycan standards are available on the market. A more general approach for the identification of glycans in a separation-based method with spectroscopic detection relies on comparing migration times (for $\mathrm{CE}$ separations) between a sample and a glycan database $(D B)$. In this case, a fully characterized glycan standard (pure or inside of a complex mixture) is analyzed once, and its migration time is stored inside a glycan DB. The DB enables identification for all further analyses without the need for spiking the glycan standard again. Accordingly, only glycan structures with known migration times can be identified. However, the buildup of a glycan DB requires a very reliable CE setup and method with very stable and reproducible migration times.

A long-term stable migration time, independent from instrument, operator, and lab, in combination with a DB, comprising a broad variety of glycan structures, eases the structural annotation. Several research groups tackled this problem in a similar way. By running an accompanying oligosaccharide standard (e.g., a glucose ladder or a set of single oligosaccharides) for each sample or set of samples, the migration time can be aligned to this standard, resulting in a standardized time axis. Hence, the migration time of individual glycan peaks can be given in standardized migration time units $(M T U)$. The MTU of a peak can now be used to search inside a dedicated DB to assign the corresponding glycan structure. Often a glucose ladder is used as an external alignment standard (in a separate run), resulting in a standardized migration 
time axis in Glucose Units $(G U)$ (Guttman et al. 1996a; Guttman and Herrick 1996; Mittermayr et al. 2013; Laroy et al. 2006; Mittermayr and Guttman 2012; Liu et al. 2007). Recently, it was shown that a co-injection of a bracketing triple internal standard (maltose, maltotriose, and maltopentadecaose; by Agilent) could negate the need for additional glucose ladder run (Jarvas et al. 2016) - at least for simple samples and regarding short term repeatability. As bigger variations of migration times in-between the bracketing standard can occur (region of interest), Hennig et al. use a patented orthogonal double alignment, combining the standard bracketing approach and the ladder approach (Hennig et al. 2015, 2016; Huffman et al. 2014), resulting in correspondingly double aligned migration time units $\left(M T U^{\prime \prime}\right)$. An alignment to the bracketing standard, labeled with the same fluorescent dye as the sample, is complemented with an orthogonal alignment to a DNA base pair standard, labeled with a different dye. Both standards are co-injected with the sample and detected in separate spectral traces. The additional DNA ladder-supporting points for the alignment significantly improved the (long-term) stability of the migration times, which allowed to build up a large $N$-glycan DB with more than 400 structures (glyXbase ${ }^{\mathrm{TM}}$ by glyXera). Recently, the glycan analysis software glyXtoolCE ${ }^{\mathrm{TM}}$ (by glyXera) was developed (Hennig et al. 2011b, 2016; glyXera 2021), which automates migration time alignment together with an instant structural assignment and furthermore provides the background adjustment raw data smoothing, peak picking, integration, relative quantification and sample comparison (Hennig et al. 2011b, 2016; Behne et al. 2013). Similar logic is behind the recent approach from Feng et al. (2017); however, alignment was performed in a non-automated fashion and with only a single normalization point to an internal glycan standard. Related bioinformatics tools such as GUcal were developed that can carry out GU value calculation in an automated fashion and concomitantly search through the database (at the moment comprised of 92 structures, available at www.glycostore.org) (GU database) for structural assignment (Jarvas et al. 2015, 2018). All these developments facilitate data processing and interpretation and make CE an easy-to-use high-throughput tool.

Nevertheless, while spiking experiments and database comparison give a strong indication of the glycan structures, they do not fully confirm them. Also, alternative approaches, when applied alone, do not allow full structural elucidation of glycans. For example, with single-stage MS, glycan composition can be estimated based upon the addition of monosaccharide constituent masses. However, glycans with different structures but identical monosaccharide composition result in identical mass values and cannot be distinguished with MS. Even with tandem mass spectrometry $(M S / M S)$, isobaric stereoisomers [like hexoses, galactose, and mannose (Man)], positional isoforms, and the different types of glycosidic linkages are difficult or impossible to determine. Here chromatographic and electrophoretic separations are advantageous with their ability to resolve closely related positional and linkage glycan isomers. Nevertheless, the structural variety of glycans is enormous, and resolution capabilities are not indefinite. Thus, what appears as a single peak often comprises a mixture of glycans (multi-structure peak). For that reason, also glycan analytical methods based on chromatographic and electrophoretic 
separation need a second dimension to provide correct and complete sample structural information. Thus, they are often complemented with an additional technique, such as MS or exoglycosidase sequencing. Principles, benefits, applications, and some limitations of exoglycosidase sequencing are outlined in the section below. A description of different $\mathrm{CE}$ and MS coupling possibilities, together with the overview of recent CE-MS-based glycomics studies, is provided in section "Coupling Capillary Electrophoresis with Mass Spectrometry."

\subsection{Exoglycosidase Sequencing of Glycans}

Exoglycosidases are enzymes that cleave the terminal carbohydrate monomers on the non-reducing end of a glycan. They can be highly selective for specific monosaccharide types (e.g., Gal, Fuc, or Man), linkage orientation ( $\alpha$ or $\beta$ ) or the position of the glycosidic linkage (e.g., 1-3, 1-4, or 2-3). Apparently, the specific enzymatic cleavage of monosaccharide residues serves as the most efficient approach for glycan structural elucidation in CE- and LC-based analysis because no additional equipment is needed. The conversion of a glycan by an exoglycosidase is harnessed with $\mathrm{CE}$ by analyzing the sample before and after the treatment. Digest-induced charge, size, and shape changes can be observed in $\mathrm{CE}$ as a change in migration time. Depending on enzyme specificity, information on monosaccharide type and the number of cleaved residues, sequence, or even linkage and anomericity can be obtained, as detailed shown by Cajic et al. (Thiesler et al. 2016) (in the supplemental material). Analysis of peak positions and relative peak areas before and after an exoglycosidase digest is therefore a means of exhaustive structural annotation. These digests can be conducted following four different strategies. First option is sequencing in a parallel fashion (Hennig et al. 2016; Thiesler et al. 2016; Feng et al. 2017), with the sample being evenly split into one aliquot per enzyme and simultaneous analysis of enzyme-treated aliquots. Second option is sequencing with parallel exoglycosidase treatments, mediated by (different) carefully designed mixtures of exoglycosidases (Szigeti and Guttman 2017; Guttman and Ulfelder 1997; Guttman 1997). Through multiple combinations of exoglycosidases (parallel enzyme array), glycans are sequenced down to their Man3-core structure (Prime and Merry 1998; Rudd and Dwek 1997). Instead of splitting the sample, it is possible to apply individual enzymes (third option) or mixtures of enzymes (fourth option) sequentially to the same sample, followed by an analysis of each step (Szigeti and Guttman 2017; Guttman et al. 2015; Mechref et al. 2005; Ma and Nashabeh 1999). This sequential treatment of a single sample is often performed when the sample amount is limited or when the sample complexity is too high. It is common practice, e.g., to reduce sample complexity by sialidase treatment before peaks are annotated (Muñoz et al. 2019; Vanderschaeghe et al. 2010; Zhuang et al. 2007, 2011). Each strategy has its advantages and drawbacks, parts of which have been already addressed elsewhere (Mittermayr et al. 2013; Prime and Merry 1998; Holland et al. 2017) and are consequently not discussed here. 
Approaches to enzymatically elucidate a glycan structure in a glycan mixture are quite diverse. For instance, it was shown that the reaction of a sequential enzyme treatment could be performed inside the CE autosampler, with the sample being injected from the enzyme reaction vial directly into CE (Szigeti and Guttman 2017). Another interesting alternative to offline methods is the incorporation of enzymes into the capillary (online digest). In-capillary enzymatic digests are a rapid option, with incubation times down to only a few minutes. By passing an enzyme plug inside the capillary, the digest of the samples is accomplished during the separation process itself (mixing via polarity switching, stopped flow or low flow incubations) (Luo et al. 2010; Holland et al. 2017; Archer-Hartmann et al. 2011a, b; Yagi et al. 2011; Gattu et al. 2017; Yamagami et al. 2017). The thermally tunable phospholipid nanogels are especially attractive due to the reported enhancement of the stability and performance of exoglycosidase enzymes (Holland et al. 2017; Yamagami et al. 2017). However, in-capillary endeavors are sometimes incompatible with certain enzymes (Yagi et al. 2011; Yamagami et al. 2017) and often accompanied by a loss in separation efficiency (Archer-Hartmann et al. 2011a, b).

Although exoglycosidases can be combined with many other methods, due to already praised advantageous features of $\mathrm{CE}$, combining the specificity of exoglycosidase enzymes with the strengths of CE seems most appropriate to determine glycan structures unambiguously and with minimum effort. Because of the high resolving power of CE, multi-structure sequencing of a complex glycan pool can be performed requiring no prior isolation of the individual glycans, resulting in significant labor and time savings. Even if enzymes are cleaving terminal residues without (much) specificity regarding linkage or position, CE can still provide this information due to its high separation efficiency. Thanks to the very good reproducibility of the peak areas, even small differences in glycan abundance can be detected reliably so that a digest-induced shift of a minor structure under a peak (less than 5\% of total peak area) can be successfully tracked. Because of the electrokinetic loading system and highly sensitive LIF detection, only a very low amount of sample is required per injection, which means that most of the sample remains for other analyses. High-throughput capabilities obtained from multi-capillary CE formats and fast separations qualify $\mathrm{CE}$ as an ideal screening method of, for example, optimal reaction conditions or batch-to-batch variations. Excellent migration time stability of some CE methods allows migration time-database matching for original and exoglycosidase digested products, making analysis much faster and more efficient. All these characteristics make $\mathrm{CE}$ in conjunction with exoglycosidase sequencing a valuable tool for detailed glycan analysis.

Despite all acknowledged benefits, the use of enzymes for determining the glycan structure requires great care and expertise and should involve a large dose of healthy skepticism about any deduced structure (Jacob and Scudder 1994). Even if certain sugar residues are exposed at the reducing end of the glycan, these residues are not always removed by the exoglycosidases with the corresponding specificities. This resistance can be due to the strict linkage specificities of the exoglycosidases, due to steric hindrance of neighboring sugar residues or due to the attached (fluorescent) label. For example, hydrolysis of bisecting GlcNAc in human IgG $\mathrm{N}$-glycans upon 
hexosaminidase treatment or the core Fuc upon bovine kidney $\alpha$-fucosidase treatment might be incomplete or completely impeded (Mittermayr et al. 2013; Laroy et al. 2006; Guttman and Ulfelder 1997; Jacob and Scudder 1994; Kamerling and Gerwig 2007; O'Flaherty et al. 2017). In addition, used enzymes may have additional selectivity for other structural features, such as local and nonlocal branching. For example, $\beta$-galactosidase can hydrolyze $\beta 1-3,4,6$-linked Gal exposed at the non-reducing end of an antenna without Fuc attached to the subterminal GlcNAc. If Fuc is attached to the antenna GlcNAc, the $\beta$-galactosidase will not hydrolyze the Gal (Yu et al. 2011). Hence, a particular exoglycosidase will cleave a terminal monosaccharide only if all its specificity requirements are met. However, the purity and composition of both glycan material and used reagents can greatly affect enzyme activity and pose an additional difficulty for accurate and reliable structural assignment (Jacob and Scudder 1994). For example, variation in enzyme activity has been observed between different batches from one vendor and different sources (vendors) of the same enzyme. Enzyme activities and side activities are often tested only on artificial p-nitrophenyl glycosides or other simple substrates, even though activity on natural complex glycans can significantly differ (Kobata 2013). Additionally, vendor-added salts or other additives have the potential to interfere with different aspects of the analysis. For instance, electrokinetic injection in $\mathrm{CE}$ is sensitive to high salt content originating from the non-volatile digestion media (Mittermayr et al. 2013; Laroy et al. 2006), which is usually unavoidable with commercial enzymes. Finally, a major issue can be the purity of the exoglycosidase. Many of the enzyme preparations contain a certain amount of contaminant enzymes, ranging from very low to unacceptably high (Jacob and Scudder 1994; Kamerling and Gerwig 2007). Therefore, even when a positive or negative result is obtained by digestion with exoglycosidases, it does not necessarily confirm the presence or absence of the corresponding sugar residues at the non-reducing end of glycan, respectively (Kobata and Takasaki 1992). Thus, using dedicated positive and negative controls for each enzyme reaction is unavoidable.

Despite the abovementioned considerations, it was shown that, when used cautiously, exoglycosidase can effectively elucidate even subtle changes in glycan structures, including linkage type (e.g., $\alpha 2-3$ versus $\alpha 2-6$ Sia or $\beta 1-3$ versus $\beta 1-4$ Gal) (Callewaert et al. 2001; Hennig et al. 2016; Konze et al. 2017; Thiesler et al. 2016), anomericity (e.g., immunogenic $\alpha$-Gal versus $\beta$-Gal) (Abeln et al. 2017; Szabo et al. 2012; Yagi et al. 2012) and position on glycan (e.g., core Fuc versus Fuc on antenna GlcNAc or Gal) (Konze et al. 2017; Thiesler et al. 2016; Meininger et al. 2016; Liu et al. 2007; Zhao et al. 2014) —a complexity which is often inaccessible by methods other than nuclear magnetic resonance (NMR) spectroscopy. 


\subsection{Coupling Capillary Electrophoresis with Mass Spectrometry}

Combining $\mathrm{CE}$, one of the most effective isomer separation tools, with the information-rich MS technique is a mutually advantageous and powerful alliance for in-depth glycan analysis. Two setups are widely applied: the direct linking of CE to MS, the so-called online CE-MS, or a time-separated analysis, the offline CEMS, in serial or parallel mode. For a serial offline approach, a CE instrument can be modified to spot the eluent from the capillary directly onto a target-plate for matrixassisted laser desorption ionization with time-of-flight MS (MALDI-TOF-MS) detection (Suzuki et al. 1997). Consequently, separation is done by CE and identification by MS. Furthermore, parallel offline approaches are gaining popularity, especially for MS-based glycopeptide or intact glycoprotein analysis (glycoproteomics). Here, the vast diversity of protein/peptide-glycan combinations (driven by the complexity of glycans) is dramatically increasing the computing time for the interpretation of MS spectra (Thaysen-Andersen and Packer 2014; Yang et al. 2017). For reduction of computing time, an initial global characterization of the $\mathrm{N}$ glycome can be performed by $\mathrm{CE}$. The resulting glycan list is used to search against a targeted set of defined $\mathrm{N}$-glycan structures as variable protein/peptide modifications (Thaysen-Andersen and Packer 2014; Parker et al. 2013; Lebede et al. 2021; Pralow et al. 2021; Pioch et al. 2018). This pre-knowledge of attached glycan structures greatly reduces the search space, which in turn significantly decreases the computing time. This allows relatively fast and in-depth analysis of quite complex samples, even with demanding glycoproteomic approaches.

The major advantage of online CE-MS is that glycans are identified by both their differential migration times and their molecular masses and/or fragmentation patterns in one analysis. The most common interface used for the transfer of glycans from the liquid phase of $\mathrm{CE}$ to the gas phase of MS is electrospray ionization (ESI) since this soft ionization method allows the direct transfer of the glycans from separation capillary to MS and is rather easy to implement. A detailed description of the advantages and drawbacks of the different interfacing options is beyond the scope of this chapter and has been already provided elsewhere (Simó and Cifuentes 2005; Maxwell and Chen 2008; Zhong et al. 2014; Zhang et al. 2017), together with the comprehensive overview of CE-MS-based glycomics studies (Pioch et al. 2012; Nakano et al. 2011; Mechref and Novotny 2009; Mechref 2013; Lindenburg et al. 2015; Dotz et al. 2015).

Although the CE-MS technology was introduced already 30 years ago (Olivares et al. 1987; Smith et al. 1988a, b) and continues to advance ever since, there has been relatively little work performed on merging CE with online electrospray MS for analysis of released glycans, in particular, when compared to the hyphenated LCMS techniques. Coupling the high resolving power of $\mathrm{CE}$ and structural information of MS in one system often comes at the expense of resolution, sensitivity, analysis time, reproducibility and/or robustness. Very often, the separation conditions giving the unmatched separation efficiency to CE are detrimental to MS performance and 
vice versa. For example, gels and buffers often used in CE because of resolution improvement are not volatile and are not suitable for CE-ESI-MS since they often suppress the ionization of the analyte, yielding poor MS sensitivity or even clog the system. On the other hand, the choice of volatile, "MS-friendly" buffers can not only affect reproducibility and analysis time but even negatively impact separations. This necessary compromise between optimal MS performance and elevated CE separation efficiency, plus its lacking robustness, are the major reasons that CE-MS has still not been widely adopted as a routine method for glycan analysis. Another concern to be addressed is that with all the limitations (small sample loads and consequent low sample concentration, sample dilution by the sheath-liquid introduction, labeling incompatibility issues, and ionization efficiency considerations) inherent in CE-MS analysis, obtaining detailed linkage and/or positional information by MS/MS is often challenging.

Even though we cannot yet talk in terms of widespread acceptance, still some efforts to make CE-MS a more viable approach in the field are ongoing. Applications are mainly limited to the use of capillary zone electrophoresis (CZE) coupled to MS for protein characterization and glycan identification. Besides the analysis of intact glycoproteins, CZE-MS is used to characterize side-specific microheterogeneity on glycopeptide level (Pioch et al. 2012; Lindenburg et al. 2015; Dotz et al. 2015). The analysis of native or derivatized glycans is often performed on complex samples (e.g., plasma $N$-glycomes), taking advantage of the good separation performance of CE (Snyder et al. 2017; Lageveen-Kammeijer et al. 2019; Huhn et al. 2012; Jayo et al. 2012). CZE-MS-based characterization of single protein glycosylation is performed less frequently (Jayo et al. 2014) and focuses mainly on monoclonal antibodies ( $m A b s$ ) (Pioch et al. 2012; Mechref 2013; Dotz et al. 2015; Gennaro and Salas-Solano 2008; Bunz et al. 2013a, b).

\subsection{Latest Developments: Miniaturization of CE Systems- Microchip CE}

Easy-to-use technologies that allow rapid and efficient screening in a compact format at the best cost are in great demand, especially in the biopharmaceutical industry. Miniaturization of the electrophoretic process onto microchips (microchip CE) holds a great promise to meet all these needs. No other technology seems better suited for miniaturization owing to two main hallmarks of CE. Firstly, sophisticated pumping systems are not necessary since the separation is driven by an applied electric field. Secondly, separation efficiency depends primarily on the strength of the electric field applied along the separation capillary and not on its length (Holland et al. 1997). Most of the commercial microchip-based systems employ relatively short separation channels $(<10 \mathrm{~cm}$, down to few millimeters) and modest electric field strengths $(<500 \mathrm{~V} / \mathrm{cm})$. However, in practice, microchip CE systems show lower separation efficiencies compared with standard CE capillary separations, 
primarily due to their shorter channel lengths. Even with this apparent disadvantage, these devices provide sufficient resolution to separate and compare all major $\mathrm{N}$ glycans found on IgG and mAbs in $60 \mathrm{~s}$ or less (Vanderschaeghe et al. 2010, 2013; Smejkal et al. 2010; Primack et al. 2011; LabChip Microfluidics 2018), illustrated in Fig. 4.2a.

The misconception that complex $N$-glycan samples are not amenable to separation by microchip CE has been proven wrong by recent research work. To increase the component resolution for these microfluidic separations, longer separation channels need to be fabricated on microchips. To keep the overall dimension of a chip turns had to be integrated into the channels without introducing significant sample dispersion. With these longer separation channels $(>20 \mathrm{~cm})$ and higher electric field strengths $(>1000 \mathrm{~V} / \mathrm{cm})$, microfluidic devices are now able to rapidly and efficiently separate $\mathrm{N}$-glycans derived even from complex samples in less than 3 min (Zhuang et al. 2007, 2011; Snyder et al. 2016, 2017; Mitra et al. 2012, 2013, 2016). Although they have great resolving power, there is often higher variability in migration times when higher separation field strengths are applied (Mitra et al. 2012).

Figure 4.2 shows a direct comparison of separations of bovine IgG-derived $\mathrm{N}$ glycans performed by microchip CE, xCGE-LIF equipped with 50 and $22 \mathrm{~cm}$ capillary-arrays, and hydrophilic interaction high-performance liquid chromatography (HILIC-HPLC). Miniaturization of the entire electrophoretic process resulted in a reasonably satisfactory separation of the major $N$-glycan peaks in seconds, as opposed to a much better separation for xCGE-LIF and HILIC-HPLC, but in minutes. However, for glycoproteins with a low glycan complexity, the capillary length in conventional CE and CGE systems can be further shortened without considerable loss of separation power, as shown for bovine IgG analyzed by xCGE-LIF with 50 and $22 \mathrm{~cm}$ capillaries (Fig. 4.2b, c). An xCGE-LIF instrument equipped with a 16-channel array with capillaries of $22 \mathrm{~cm}$ in length has an effective separation time of $32 \mathrm{~s}$ per sample ( $8.5 \mathrm{~min} / 16$ samples), which is close to $22.5 \mathrm{~s}$ obtained by the chip-CE instrument, but with a significantly better separation of the $N$-glycan peaks. Keeping the multiplexing aspect of xCGE-LIF in mind, with its possibility to run up to 96 samples in parallel, it becomes obvious that there is potential to further increase the throughput of microchip CE.

Thus, despite the mentioned advancements, "Lab-on-a-chip" technology—incorporating both sample preparation and analysis onto the same microfluidic devices with a minimum hands-on time and being sufficiently simple for non-experts—still remains an ultimate goal. But first, the current generation of miniaturized systems has yet to demonstrate benefits in cost and performance, compelling enough to make them seriously competitive with conventional benchtop-scale CE technology. This is reflected in the current market volatility. The reliable availability of equipment, consumables, or support can often not be guaranteed. Therefore, low-cost, reliable and highly efficient microchip CE systems are expected to encourage greater use of this technology in the glycomics field. 
A $\quad$ Microchip CE

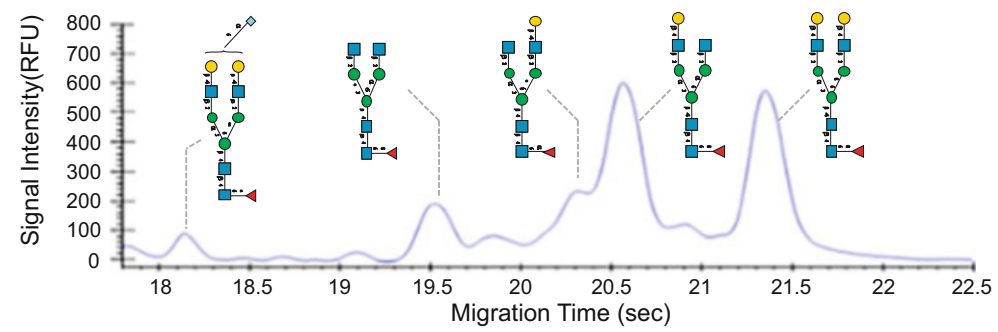

B

xCGE-LIF (50 cm capillary)

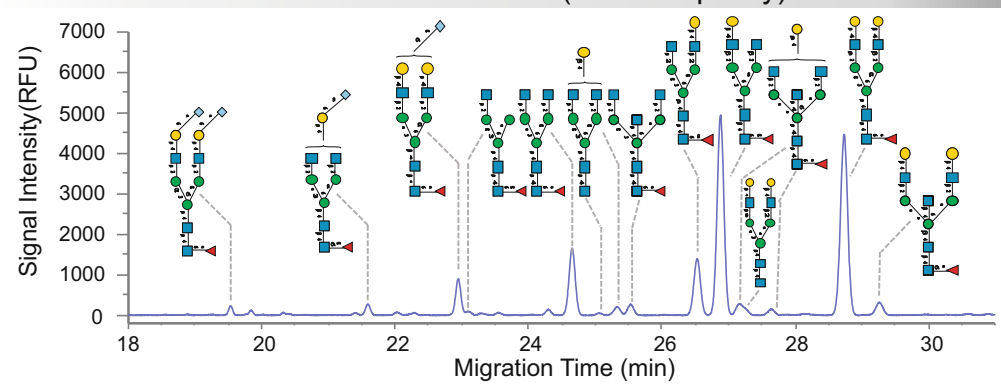

C

xCGE-LIF (22 cm capillary)

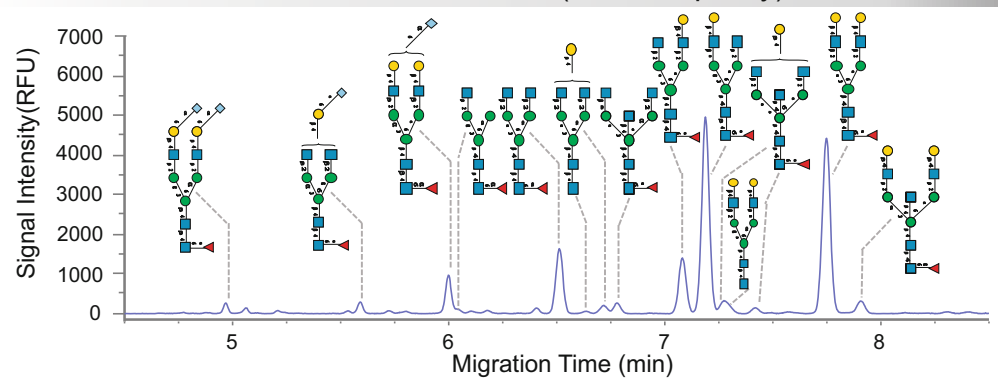

D HILIC-UPLC-FLD

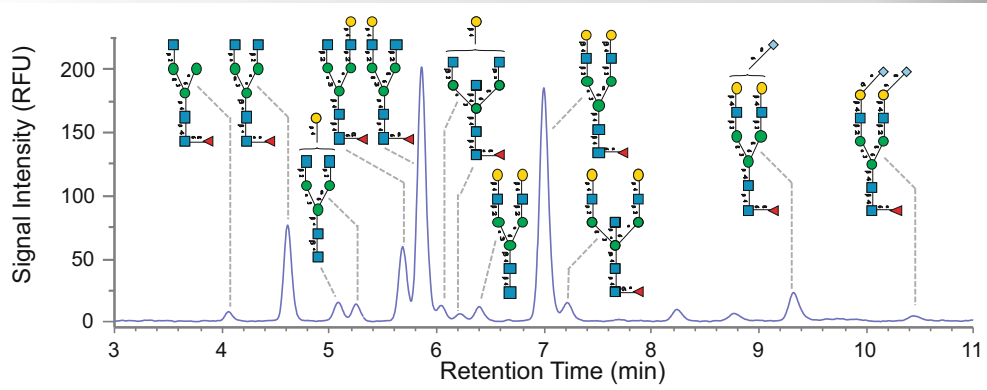

Fig. 4.2 Bovine IgG $N$-glycome analysis on the (a) PerkinElmer LabChip GXII Touch (microchip CE), (b and c) glyXera glyXboxCE ${ }^{\mathrm{TM}}$ built on Applied Biosystems Genetic Analyzer 3130 (xCGE- 


\subsection{Application of $\mathbf{C}(\mathrm{G}) \mathrm{E}$ for Immunoglobulin Analysis}

Compared to common LC- and MS-based approaches, CE-based glycan analysis approaches are lagging far behind with respect to the number of applications and publications. This is largely due to the existing obstacles that needed to be tackled, including missing kits for sample preparation and non-flexible, difficult to handle or often unstable instruments. However, as discussed in detail in the previous sections, all these initial difficulties are now solved. Since stable and easy-to-handle DNA analyzers were adopted for $\mathrm{N}$-glycan analyses by Callewaert and coworkers (Callewaert et al. 2001; Laroy et al. 2006), this approach gained popularity in the field of glycomics. Moreover, the availability of commercial analysis kits and instrumental solutions [e.g., by glyXera, PerkinElmer, Prozyme/Agilent, Sciex and Thermo Fisher Scientific (glyXera 2020; Thermo Fisher Scientific 2018; ProZyme 2018; SCIEX 2018; PerkinElmer 2018)], including software and glycan databases, made $\mathrm{C}(\mathrm{G})$ E-based methods appealing to the scientific community, as well as to the biopharmaceutical industry. This broader acceptance can be additionally attributed to the separation power of $\mathrm{C}(\mathrm{G}) \mathrm{E}$ and the ability to resolve complex glycan mixtures and to separate positional and linkage isomers. The following paragraphs are intended to highlight significant applications of $\mathrm{C}(\mathrm{G}) \mathrm{E}$ to the analyses of $N$-glycans in the science and biopharmaceutical industry and some new, exciting possibilities with a special emphasis on immunoglobulins.

IgG The $\mathrm{C}(\mathrm{G}) \mathrm{E}$-based analysis of IgG $N$-glycosylation is well established (Reusch et al. 2014, 2015a; Routier et al. 1998) and was already applied to big cohorts (Huffman et al. 2014). Small sample quantities required for the xCGE-LIF-based analysis turned out to be quite beneficial for studies with limited sample availability, e.g., for the analysis of mouse IgG $N$-glycosylation (Patenaude et al. 2020; Schaffert et al. 2020). Consequently, this method can be applied to all kinds of mammalian samples, from large to small. As an example, Fig. 4.3 shows a comparison of the IgG $N$-glycans derived from various mammalian species, namely human, cow, mouse, $\mathrm{dog}$, and rabbit. Human and bovine (cow) IgG-derived $\mathrm{N}$-glycans show quite some similarities, despite the absence of the Neu5Gc sialic acid type in humans, respectively of Neu5Ac in cow (Raju et al. 2000). However, more dominant are the differences between the species. Their IgG $N$-glycomes vary in composition and

Fig. 4.2 (continued) LIF), (d) Dionex Ultimate 3000RS UPLC system equipped with Waters ACQUITY UPLC Glycan BEH Amide column. For (a), labeled bovine IgG $N$-glycans were prepared using the PerkinElmer Glycan Profiling Assay Reagent Kit (PerkinElmer 2018). For (b) and (c), APTS-labeled $\mathrm{N}$-glycans were prepared from bovine IgG following a published procedure (Hennig et al. 2016; Huffman et al. 2014). For (d), $N$-glycans were enzymatically released from bovine IgG, AB-labeled (Ruhaak et al. 2010c) and subsequently purified (Ruhaak et al. 2008, 2012) before measurement by HILIC-UPLC-FLD. The signal intensity of the $y$-axis is given in relative fluorescence units (RFU). Symbolic representation of $N$-glycan structures follows the guidelines of Symbol Nomenclature for Glycans (SNFG) (Varki et al. 2015) 


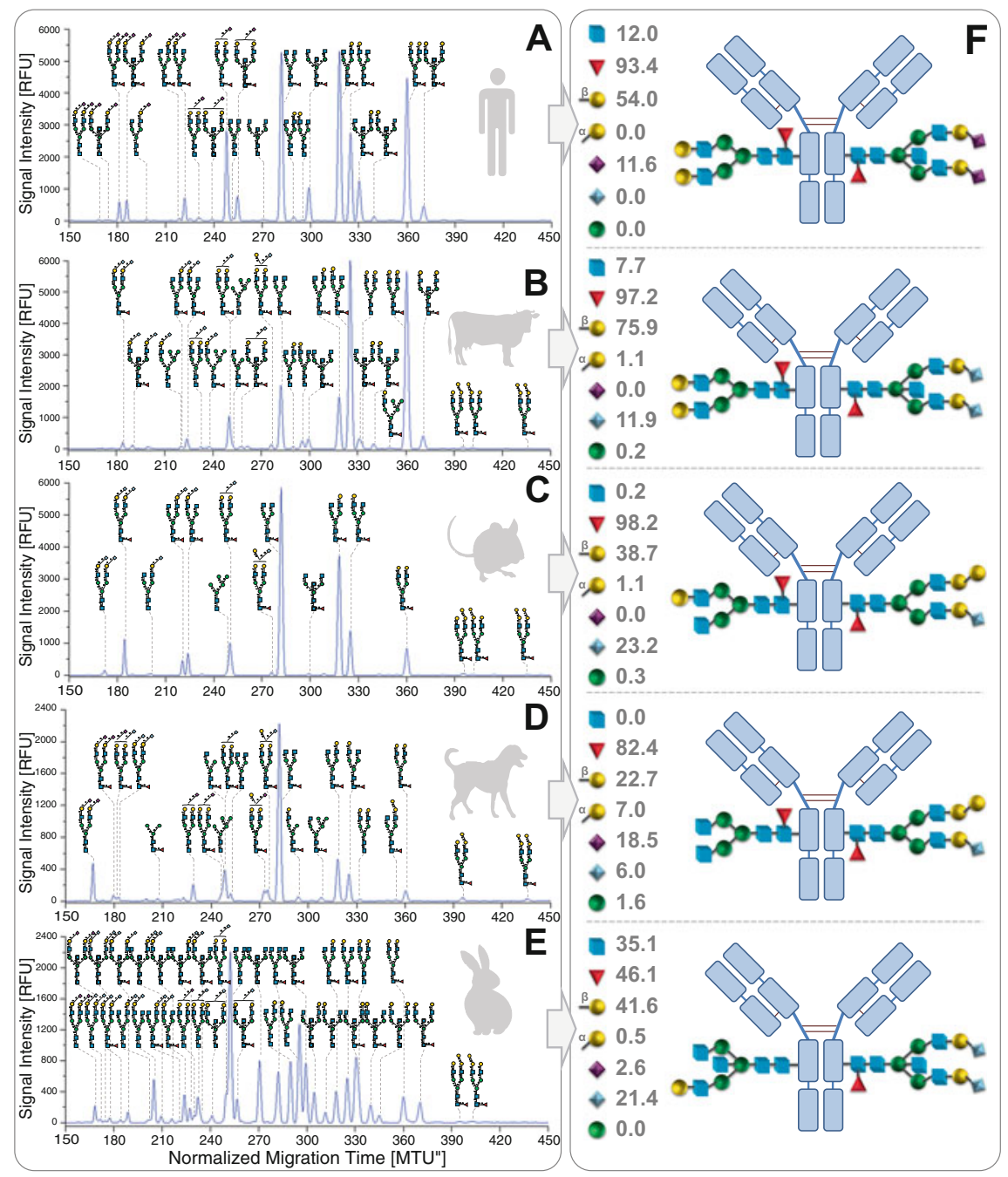

Fig. 4.3 Species-specific IgG $N$-glycosylation analyzed by xCGE-LIF. xCGE-LIF generated fingerprints of APTS-labeled $N$-glycans derived from human $\operatorname{IgG}(\mathbf{a})$, bovine $\operatorname{IgG}(\mathbf{b})$, mouse $\operatorname{IgG}$ (c), dog IgG (d) and rabbit IgG (e) (Vendors: Dog IgG-Abcam, other IgGs-Sigma-Aldrich). APTS-labeled $N$-glycans were prepared using the glyXprep ${ }^{48}$ kit (glyXera 2020) by carefully following the kit instructions. Data processing was performed using glyXtoolCE ${ }^{\mathrm{TM}}$ (glyXera 2021). Data processing comprised alignment of migration times to two orthogonal internal standards, resulting in a double aligned $\mathrm{x}$-axis in migration time units $\left(\mathrm{MTU}^{\prime \prime}\right)$. The signal intensity of the $\mathrm{y}$-axis is given in relative fluorescence units (RFU). $\mathrm{N}$-glycan structures were assigned via database matching using glyXtoolCE ${ }^{\mathrm{TM}}$ (in combination with glyXbase ${ }^{\mathrm{TM}}$ ) and confirmed by exoglycosidase sequencing as published by Thiesler et al. (2016). (f) Overview of IgG $N$-glycome characteristics with: blue square for bisected $N$-glycans, red triangle for core fucosylated $N$-glycans, yellow circle for glycans with terminal galactose in $\beta 1-4$ or $\alpha 1-3$ linkage, purple diamond for glycans with terminal $N$-acetylneuraminic acid (Neu5Ac), light blue diamond for glycans with terminal $\mathrm{N}$-glycolylneuraminic acid (Neu5Gc) and green circle for oligo-mannosidic $\mathrm{N}$-glycans. 
abundance of different glycans; from quite simple mixtures of glycans, with only a few structures (like the murine/mouse IgG in Fig. 4.3c), to extremely complex mixtures, with a wide range of structures, as shown in Fig. 4.3e for leporid (rabbit) IgG. Due to the big proportion of bisected $N$-glycans, in combination with a low degree of galactosylation and fucosylation, leporid IgG-derived $\mathrm{N}$-glycans show one of the most complex glycosylation patterns (Taniguchi et al. 1985), which is still well resolved by xCGE-LIF, compared to results achieved by HILIC-UPLC analysis (Vainauskas et al. 2016). Additionally, the ability to separate Neu5Ac from Neu5Gc, as shown for canine (dog) IgG in Fig. $4.3 \mathrm{~d}$ at about $180 \mathrm{MTU}^{\prime \prime}$, exposes the big potential of $\mathrm{C}(\mathrm{G}) \mathrm{E}$-based glycan analysis techniques. As recombinant IgGs produced in different host cells is one of the major therapeutic agents to treat life-threatening diseases (Raju et al. 2000), fast and effective analysis of speciesspecific glycosylation differences by methods like $\mathrm{C}(\mathrm{G}) \mathrm{E}$ is becoming invaluable in this field.

Other Igs Humans have five distinct classes of Igs, namely $\operatorname{IgA}$, IgD, $\operatorname{IgE}$, IgG, and IgM. All Igs are comprised of two heavy and two light chains that are joined together by disulfide bonds. The glycosylation of Igs greatly varies between the different classes, ranging from only one conserved $\mathrm{N}$-glycosylation site in $\mathrm{IgG}$ up to various $\mathrm{N}$ - and $O$-glycosylation sites for IgD (Maverakis et al. 2015; Clerc et al. 2016). It has long been known that aberrant IgA glycosylation causes IgA nephropathy and Henoch-Schoenlein purpura nephritis (Allen et al. 1995; Novak et al. 2007), and it was recently discovered that $\mathrm{IgE}$ sialylation is one regulator of allergic reactions (Shade et al. 2020). But, although Igs are the major component of the adaptive immune system, only little is known about the influence of their glycosylation, apart from the extensively studied IgG. This is partially due to current technological limitations and the complexity of their glycosylation (Maverakis et al. 2015).

Here, we show how to overcome these limitations by giving a comprehensive overview on $N$-glycosylation of all plasma immunoglobulins, analyzed by xCGELIF as shown in Fig. 4.4. In contrast to human IgG with incomplete sialylation (Fig. 4.4d), human IgA, IgD, IgE, and IgM show a high degree of sialylation—often in combination with a big variety of oligo-mannosidic $\mathrm{N}$-glycan structures (Fig. 4.4a-c, e). In comparison to HILIC-HPLC results published in the early 2000s (Arnold et al. 2004, 2005; Mattu et al. 1998), the xCGE-LIF results display markedly better resolution, resolving structures appearing as multi-structure peaks in HILIC-HPLC. Guttman and coworkers achieved similar results using a CE-based

Fig. 4.3 (continued) Numbers indicate their approximated relative abundances in percent. IgG illustrations indicate the broad characteristics of the $\mathrm{N}$-glycan structures attached to the speciesspecific IgGs. IgG illustrations are for visualization purposes only and do not reflect a real combination of $\mathrm{N}$-glycans or their linkage position to the protein backbone. Symbolic representation of $\mathrm{N}$-glycan structures follows the guidelines of Symbol Nomenclature for Glycans (SNFG) (Varki et al. 2015) 

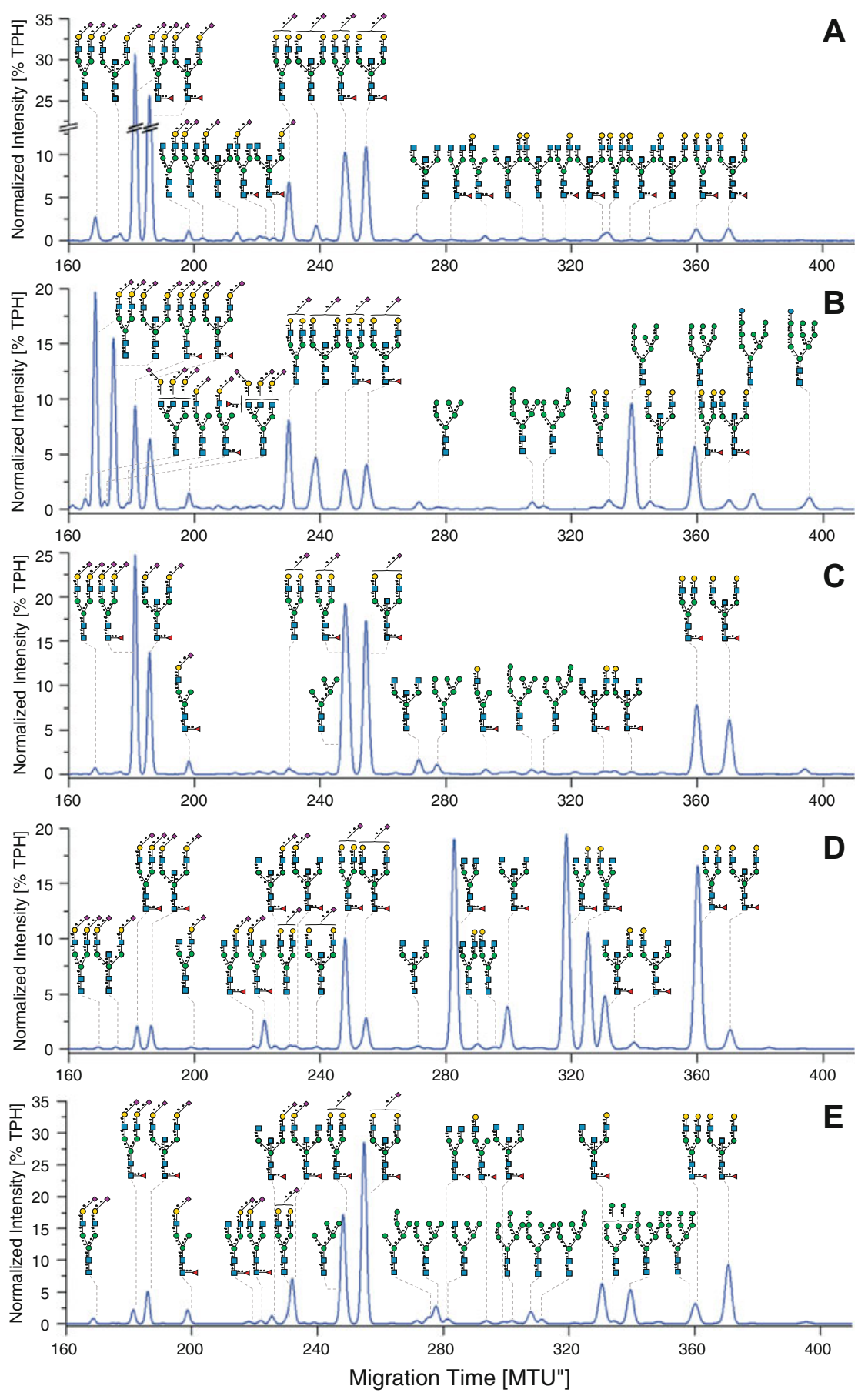

Fig. 4.4 $N$-glycan analysis of all human serum immunoglobulins by xCGE-LIF. xCGE-LIF generated fingerprints of APTS-labeled $N$-glycans derived from human $\operatorname{IgA}(\mathbf{a}), \operatorname{IgD}(\mathbf{b}), \operatorname{IgE}(\mathbf{c})$, $\operatorname{IgG}$ (d) and IgM (e) (Vendor: Abcam for IgA, IgD, IgE, and IgM; Sigma-Aldrich for IgG). 
approach for the analysis of IgA from blood and saliva (Meszaros et al. 2020). They applied the method to biomedically relevant samples and found a link between altered IgA $N$-glycosylation and oral mucositis (Gebri et al. 2020). As the role of Ig glycosylation (besides IgG) is still not fully understood, xCGE-LIF might therefore simplify and speed up data generation and interpretation-thus, in the future promote interesting new findings when applied to big cohort studies.

Fab and Fc Antibody Domains A general approach in the field of glycobiology is to analyze released $\mathrm{N}$-glycans of the entire $\operatorname{IgG}$ (the $\operatorname{IgG~} N$-glycome) (Huffman et al. 2014). However, $N$-glycans can appear at two different positions on IgG. The majority of $N$-glycans are attached to the conserved $N$-glycosylation site inside the constant (Fragment crystallizable, $F c$ ) domain, while only a minor portion of $N$ glycans (up to 20\%) might originate from the variable (Fragment antigen binding, $\mathrm{Fab}$ ) domain of IgG (van de Bovenkamp 2019). The so-called Fab $\mathrm{N}$-glycans differ from those attached to the Fc part, as the Fab portion possesses primarily highly sialylated and bisected complex type $N$-glycans (Clerc et al. 2016; van de Bovenkamp 2019), as shown in Fig. 4.5b (black curve), compared with the Fc-associated glycans with lower sialylation, as shown in Fig. 4.5b (blue curve). Having a global look at glycosylation of other human immunoglobulins (Fig. 4.4), the Fab glycosylation shows high similarity. The higher degree of sialylation in Fab-associated glycans of $\mathrm{IgG}$ might originate in part from selective removal of non-sialylated structures by the hepatic asialo-glycoprotein receptor $(H A G R$ ) (as for $\operatorname{IgA}, \operatorname{IgD}, \operatorname{IgE}, \operatorname{IgM}$, and all other blood proteins), resulting in a plasma glycoprotein typical glycosylation (Dalziel et al. 1999). Fc-associated glycans are less accessible ("hidden"), and accordingly not cleared from the bloodstream by HAGR. Furthermore, the presumably better accessibility of the IgG Fab glycosylation site to glycosyltransferases results in better processing compared to $\mathrm{Fc}$ glycans that are spatially localized inside the constant domain and not accessible to the same enzymes (van de Bovenkamp 2019).

Unfortunately, many big cohort studies of IgG glycosylation are focusing on released $\mathrm{N}$-glycans and are not differentiating between IgG Fab- and Fc $N$-glycosylation (Huffman et al. 2014; Wang et al. 2017; Russell et al. 2017; Barrios et al. 2016; Trbojevic Akmacic et al. 2015; Lauc et al. 2013; Pučić et al. 2011), although recent studies suggest that the prevalence and complexity of Fab glycans might

Fig. 4.4 (continued) APTS-labeled $N$-glycans were prepared using the glyXprep ${ }^{48}$ kit (glyXera 2020), by carefully following the kit instructions. Data processing was performed using glyXtoolCE ${ }^{\mathrm{TM}}$ (glyXera 2021). Data processing comprised alignment of migration times to two orthogonal internal standards, resulting in a double aligned $\mathrm{x}$-axis in migration time units $\left(\mathrm{MTU}^{\prime \prime}\right)$. Peak heights were normalized to the sum of all peaks, resulting in a normalized intensity in $\%$ of total peak height (TPH). $N$-glycan structures were assigned via database matching using glyXtoolCE ${ }^{\mathrm{TM}}$ (in combination with glyXbase ${ }^{\mathrm{TM}}$ ) and confirmed by exoglycosidase sequencing as published by Cajic et al. (Thiesler et al. 2016). Symbolic representation of $N$-glycan structures follows the guidelines of Symbol Nomenclature for Glycans (SNFG) (Varki et al. 2015) 

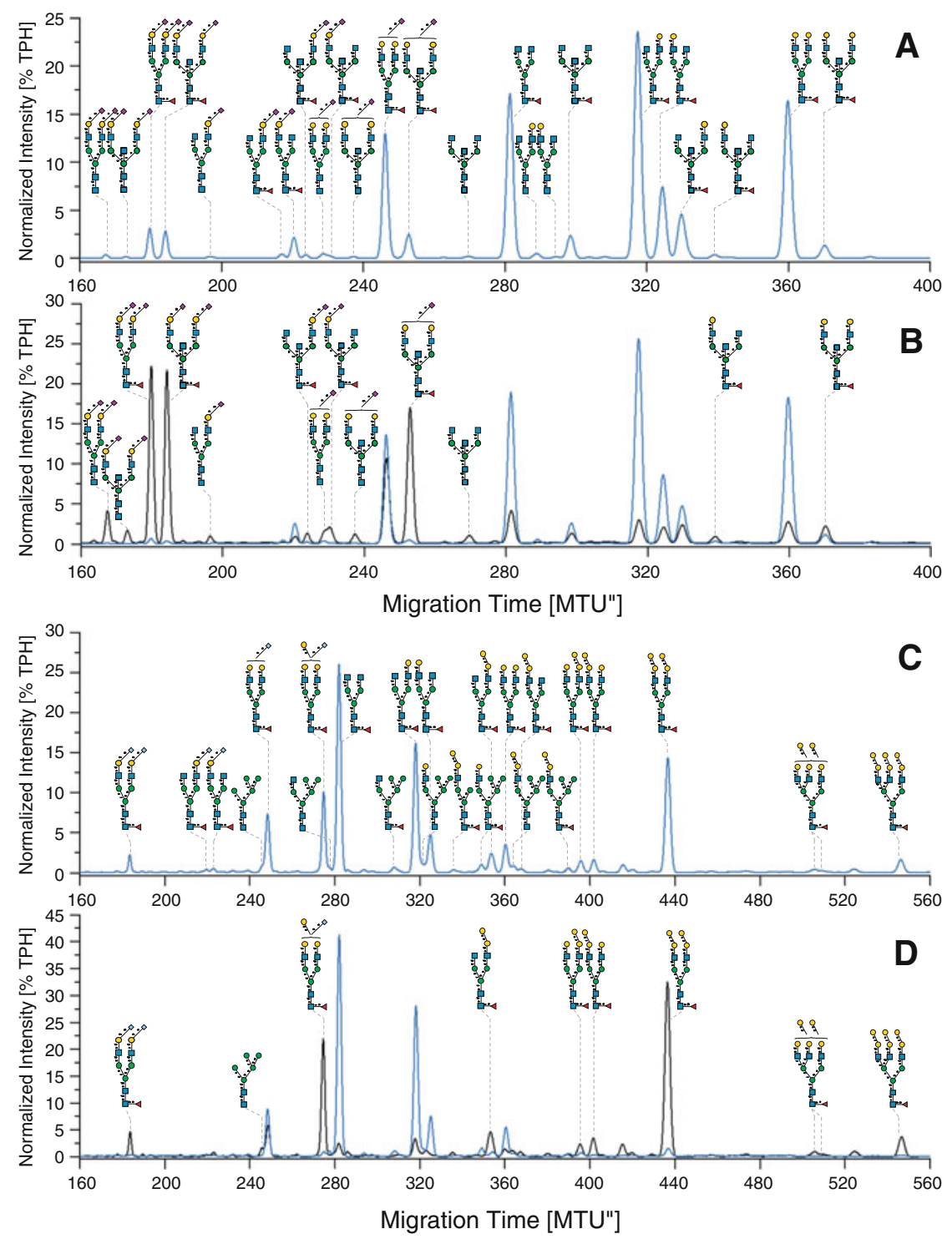

Fig. 4.5 Fab and Fc glycosylation analysis by xCGE-LIF, exemplarily shown for human IgG and the SP2/0 cell-derived mAb cetuximab (Erbitux). xCGE-LIF generated fingerprints of APTSlabeled $\mathrm{N}$-glycans derived from: whole human $\operatorname{IgG}(\mathbf{a})$, human IgG Fab (b, black curve), human IgG Fc (b, blue curve), whole mAb cetuximab (c), cetuximab Fab (d, black curve) and cetuximab Fc (d, blue curve) (human IgG was purified from normal control plasma, purchased at Affinity Biologicals; cetuximab was purchased at Evidentic). Fab and $\mathrm{Fc}$ part of human $\mathrm{IgG}$ and $\mathrm{mAb}$ cetuximab were purified and generated as published by Bondt et al. (2014). Release and APTSlabeling of $N$-glycans were performed, using the glyXprep ${ }^{48}$ kit (glyXera 2020), by carefully following the kit instructions. Data processing was performed using glyXtoolCE ${ }^{\mathrm{TM}}$ (glyXera 2021). Data processing comprised alignment of migration times to two orthogonal internal standards, resulting in a double aligned $\mathrm{x}$-axis in migration time units (MTU"). Peak heights were 
change for certain physiological and pathological conditions. On the one hand, sialylated Fab glycans are presumed to be protective during pregnancy (Bondt et al. 2014), while on the other hand, an increase in Fab glycans is associated with several autoimmune diseases, like rheumatoid arthritis and Sjögren's syndrome, or cancer like multiple myeloma (Kinoshita et al. 1991). These aspects show that a separate analysis of Fab and Fc glycosylation might be beneficial for a better understanding of immunological processes and that Fab and Fc glycans might be a promising biomarker for the early detection of various diseases. Here, especially $\mathrm{C}(\mathrm{G})$ E shows big potential because of its high sensitivity — enabling detection of even the lowest amounts of Fab glycans (Fig. 4.5b), and its speed (by multiplexing)enabling higher sample throughput if needed.

Therapeutic Glycoproteins Since glycosylation of monoclonal antibodies (mAb) is a critical quality attribute (CQA), the detailed characterization and control of antibody glycosylation during the development process and later product life cycle is essential. Despite the ever-growing use of $\mathrm{C}(\mathrm{G}) \mathrm{E}$-based methods for biopharmaceutical characterization, the number of publications in the field is still quite limited (Reusch et al. 2014; Croset et al. 2012; Bunz et al. 2013a; Bielser et al. 2020; Borza et al. 2018). Nevertheless, several studies showed that the CGE-based analysis results are quite comparable to the results obtained with conventional MS- and LC-based methods (Reusch et al. 2015a, b; De Leoz et al. 2020). As shown for the $\mathrm{SP} 2 / 0$ cell-derived mAb cetuximab in Fig. $4.5 \mathrm{c}$, d, the overall results are quite comparable to the earlier analysis results achieved with HILIC-HPLC and MALDI-TOF MS (Qian et al. 2007), or ESI-TOF MS (Janin-Bussat et al. 2013). Here xCGE-LIF could also resolve the isomeric structures containing the immunogenic $\alpha$-Gal from non-immunogenic $\beta$-Gal for Fc, Fab (Fig. 4.5d) and complete mAb $N$-glycosylation (Fig. 4.5c). After the discovery that the $\alpha 1-3$ Gal epitope can cause an anaphylactic shock via an anti-oligosaccharide IgE-mediated reaction (Chung et al. 2008; Chinuki and Morita 2019), the absence of this epitope is intended for all newly developed therapeutic glycoproteins and biosimilars. Nevertheless, several previously commercialized mAbs are produced in murine hybridoma cell lines like NS0 and SP2/0, which do express the $\alpha 1-3$ Gal epitope (Qian et al. 2007; Uçaktürk 2012; Stadlmann et al. 2008), as shown in Fig. 4.6a for the comparison of $\mathrm{NSO}$-derived mAb ramucirumab (Cyramza) (blue line) and SP2/0-derived mAb cetuximab (Erbitux) (black line). In contrast, the current dominant production cell lines are derived from Chinese Hamster Ovary $(\mathrm{CHO})$ cells, which do not express the immunogenic $\alpha 1-3$ Gal epitope, as shown in Fig. 4.6b. Accordingly, the $\alpha 1-3$ Gal epitope can be used to identify the production cell line of a mAb in a

Fig. 4.5 (continued) normalized to the sum of all peaks, resulting in a normalized intensity in \% of total peak height (TPH). $\mathrm{N}$-glycan structures were assigned via database matching using glyXtoolCE ${ }^{\mathrm{TM}}$ (in combination with glyXbase ${ }^{\mathrm{TM}}$ ) and confirmed by exoglycosidase sequencing as published by Cajic et al. (Thiesler et al. 2016). Symbolic representation of $N$-glycan structures follows the guidelines of Symbol Nomenclature for Glycans (SNFG) (Varki et al. 2015) 

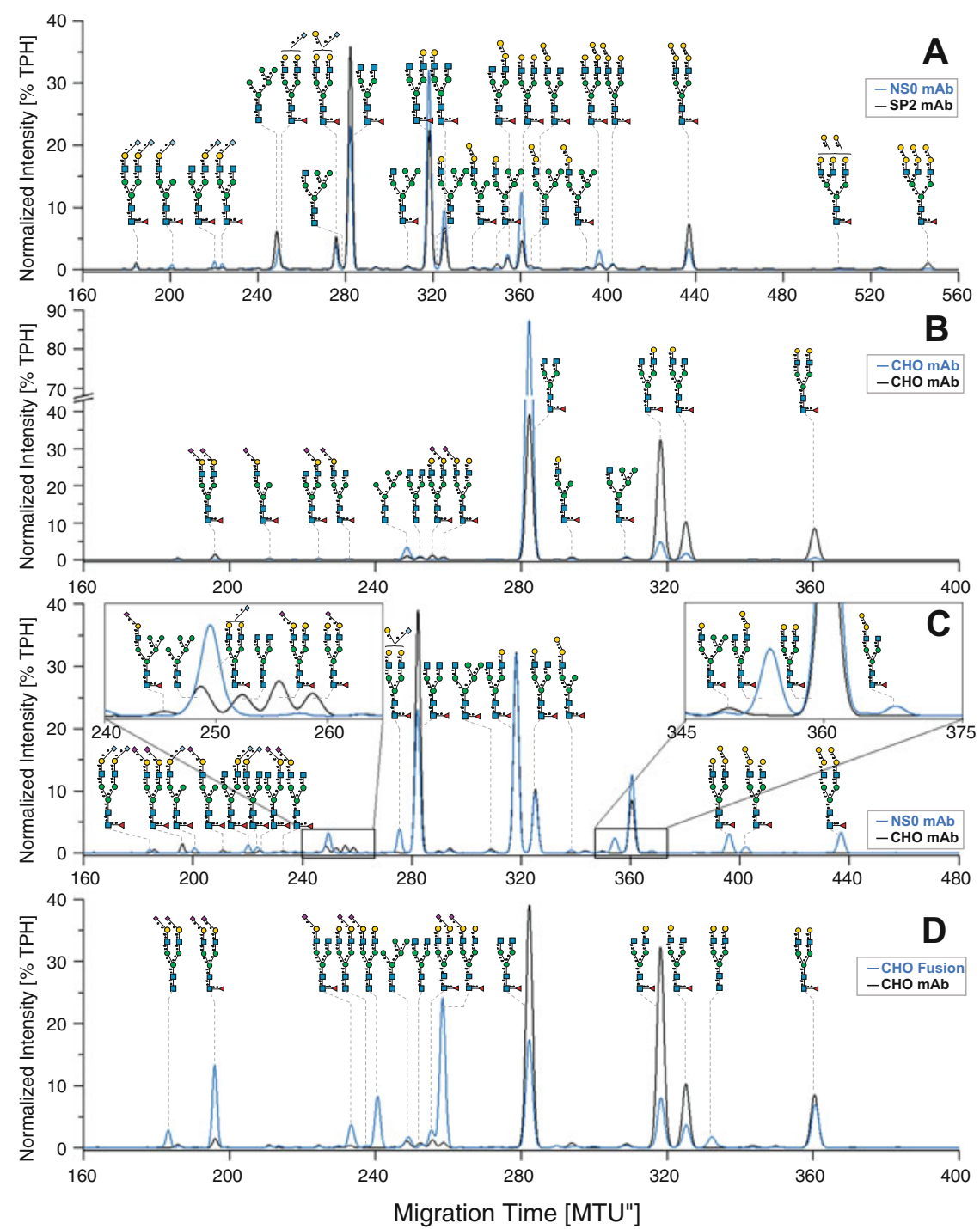

Fig. 4.6 xCGE-LIF-based $N$-glycan analysis comparing the therapeutic proteins ramucirumab (NS0), cetuximab (SP2/0), bevacizumab (CHO), rituximab (CHO) and etanercept (CHO). xCGELIF generated fingerprints of APTS-labeled $N$-glycans derived from mAb ramucirumab (Cyramza) produced in NS0 cells (a and $\mathbf{c}$; blue curve), mAb cetuximab (Erbitux) produced in SP2/0 cells (a; black curve), mAb bevacizumab (Avastin ${ }^{\circledR}$ ) produced in CHO cells (b; blue curve), mAb rituximab produced in CHO cells $\left(\right.$ Rituxan $\left.{ }^{\circledR}\right)\left(\mathbf{b}, \mathbf{c}\right.$ and $\mathbf{d}$; black curve) and fusion protein etanercept (Enbrel ${ }^{\mathbb{B}}$ ) produced in CHO cells (d; blue curve) (all purchased at Evidentic). Release and APTS-labeling of $N$-glycans were performed using the glyXprep ${ }^{48}$ kit (glyXera 2020), by carefully following the kit instructions. Data processing was performed using glyXtoolCE ${ }^{\mathrm{TM}}$ (glyXera 2021). Data processing comprised alignment of migration times to two orthogonal internal standards, resulting in a double aligned $\mathrm{x}$-axis in migration time units $\left(\mathrm{MTU}^{\prime \prime}\right)$. Peak heights were normalized to the sum of all peaks, resulting in a normalized intensity in \% of total peak height (TPH). $N$-glycan structures were assigned via database matching using glyXtoolCE ${ }^{\mathrm{TM}}$ (in combination with glyXbase ${ }^{\mathrm{TM}}$ ) and 
straightforward manner, as shown for comparison of the CHO-derived mAb rituximab $\left(\right.$ Rituxan ${ }^{\circledR}$ ) (black line) and the NSO derived mAb ramucirumab (blue line) in Fig. 4.6c (zoom-in around $360 \mathrm{MTU}^{\prime \prime}$ ). However, CHO cells are differing from NS0 and SP2/0 cells in two additional important $N$-glycosylation properties: $\mathrm{CHO}$ cells incorporate mainly the non-immunogenic Neu5Ac in $\alpha 2-3$ linkage, as representatively shown for the mAbs bevacizumab $\left(\right.$ Avastin $^{\circledR}$ ) (blue line) and rituximab (black line) in Fig. 4.6b and the fusion protein etanercept (Enbrel ${ }^{\circledR}$ ) (blue line) in Fig. 4.6d (Borza et al. 2018; Mcleod 2013). In contrast, NS0 and SP2/0 cells integrate Neu5Gc in $\alpha 2-6$ linkage (Qian et al. 2007; Stadlmann et al. 2008; Beck et al. 2008), as shown for SP2/0-derived cetuximab in Fig. 4.5c, d and ramucirumab in Fig. 4.6a. This enables an easy distinction between originator and biosimilar mAb, as both structural $N$-glycan properties (Neu5Gc versus Neu5Ac and $\alpha 2-3$ versus $\alpha 2-6$ linkage) can be directly resolved by XCGE-LIF, without the need for an additional exoglycosidase treatment, as shown in detail for the zoom-in around $250 \mathrm{MTU}^{\prime \prime}$ in Fig. 4.6c. Furthermore, the high resolution of xCGE-LIF enables the monitoring of structural $\mathrm{N}$-glycan properties of glycoengineered $\mathrm{CHO}$ cells, like the missing core fucose of FUT8 knockout CHO cells (Yamane-Ohnuki et al. 2004), the additional bisected GlcNAc for GnTIII over-expression CHO cells (Umaña et al. 1999), or the emerging $\alpha 2-6$-linked Neu5Ac in CHO cells with stable ST6GAL1 expression (Houeix and Cairns 2019).

Besides the resolution of structural properties of $\mathrm{N}$-glycans, the relative quantities (like the degree of galactosylation or sialylation) are easily accessible, too. As demonstrated for the mAbs bevacizumab and rituximab in Fig. 4.6b, remarkable differences in $N$-glycosylation can be observed. While bevacizumab has a considerably low degree of galactosylation (with about $90 \%$ of all $\mathrm{N}$-glycans gathered in only one peak comprising of FA2G0), rituximab shows a more complex $N$-glycosylation pattern (with di-antennary $N$-glycans bearing up to two terminal sialic acids). In the case of sialylation, both mAbs are clearly lagging behind the fusion protein etanercept (tumor necrosis factor receptor linked to the Fc portion of human IgG1) with a sialylation degree of more than $50 \%$. These differences in the $\mathrm{N}$ glycosylation are often intentionally induced, as they affect the proper function of the protein (Kanda et al. 2007), its stability and thus the product potency and quality.

Moreover, xCGE-LIF is a powerful tool for high-throughput screening of hundreds of cell clones during early-stage discovery, as well as post-discovery characterization, with minimal material consumption and costs. Here, xCGE-LIF-based methods help to reduce the screening time, greatly accelerating the development of biosimilars, biobetters, and new biotherapeutics. In combination with commercially available enzymes like IdeZ (by New England Biolabs) or FabRICATOR ${ }^{\circledR}$ (Z) (by Genovis), "site"-specific characterization of IgG-based therapeutic proteins can be achieved, ensuring a more detailed level of protein characterization, and

Fig. 4.6 (continued) confirmed by exoglycosidase sequencing as published by Cajic et al. (Thiesler et al. 2016). Symbolic representation of $\mathrm{N}$-glycan structures follows the guidelines of Symbol Nomenclature for Glycans (SNFG) (Varki et al. 2015) 
preventing surprises during pharmacokinetic testing. Consequently, xCGE-LIF holds potential toward detailed analysis of $\mathrm{mAb}$ glycosylation in real high throughput.

\subsection{Conclusion}

CE has matured to the point that it can stay side by side with other more commonly used techniques for glycan analysis. Because of its unbeatable speed, resolution, sensitivity, and simplicity, the method is gaining more and more attention. Ongoing efforts to bring CE-based analysis kits and software solutions on the market (together with the increasing availability, size, and quality of glycan databases) will make the method attractive to the biopharmaceutical industry, helping to reveal the full potential of therapeutic glycoproteins like mAbs. Application of CE-based workflows for Ig analysis will enable more detailed characterization of their glycosylation and fast, automated high-throughput monitoring of their glycosylation patterns, especially when employed for large cohort studies. The recent and upcoming developments in miniaturization and analysis toolboxes show that there is an exciting future in glycan analysis for this recently revived technology.

\section{Compliance with Ethical Standards}

Funding Erdmann Rapp acknowledges support by Deutsche Forschungsgemeinschaft (DFG, German Research Foundation)—Project-ID RA2992/1-1—Forschungsgruppe FOR 2509. Robert Burock acknowledges support by funds of the ESF.

Conflict of Interest Author Erdmann Rapp is the founder, CEO and CSO of glyXera GmbH. Authors René Hennig and Robert Burock are employees of glyXera GmbH. glyXera provides highperformance glycoanalytical products and services and holds several patents for XCGE-LIF based glycoanalysis. Author Samanta Cajic declares no competing interests.

Ethical Approval This article does not contain any studies with human participants or animals performed by any of the authors.

\section{References}

Abeln M, Borst KM, Cajic S, Thiesler H, Kats E, Albers I et al (2017) Sialylation is dispensable for early murine embryonic development in vitro. ChemBioChem 18(13):1305-1316

Allen AC, Harper SJ, Feehally J (1995) Galactosylation of N- and O-linked carbohydrate moieties of IgA1 and IgG in IgA nephropathy. Clin Exp Immunol 100(3):470-474

Anthony RM, Nimmerjahn F, Ashline DJ, Reinhold VN, Paulson JC, Ravetch JV (2008) Recapitulation of IVIG anti-inflammatory activity with a recombinant IgG Fc. Science 320 (5874):373-376

Archer-Hartmann SA, Sargent LM, Lowry DT, Holland LA (2011a) Microscale exoglycosidase processing and lectin capture of glycans with phospholipid assisted capillary electrophoresis separations. Anal Chem 83(7):2740-2747 
Archer-Hartmann SA, Crihfield CL, Holland LA (2011b) Online enzymatic sequencing of glycans from Trastuzumab by phospholipid-assisted capillary electrophoresis. Electrophoresis 32 (24):3491-3498

Arnold JN, Radcliffe CM, Wormald MR, Royle L, Harvey DJ, Crispin M et al (2004) The glycosylation of human serum $\operatorname{IgD}$ and $\operatorname{IgE}$ and the accessibility of identified oligomannose structures for interaction with mannan-binding lectin. J Immunol 173(11):6831-6840

Arnold JN, Wormald MR, Suter DM, Radcliffe CM, Harvey DJ, Dwek RA et al (2005) Human serum IgM glycosylation: identification of glycoforms that can bind to Mannan-binding lectin. $\mathrm{J}$ Biol Chem 280(32):29080-29087

Barrios C, Zierer J, Gudelj I, Stambuk J, Ugrina I, Rodríguez E et al (2016) Glycosylation profile of IgG in moderate kidney dysfunction. J Am Soc Nephrol 27(3):933-941

Beck A, Wagner-Rousset E, Bussat M-C, Lokteff M, Klinguer-Hamour C, Haeuw J-F et al (2008) Trends in glycosylation, glycoanalysis and glycoengineering of therapeutic antibodies and Fc-fusion proteins. Curr Pharm Biotechnol 9(6):482-501

Behne A, Muth T, Borowiak M, Reichl U, Rapp E (2013) glyXalign: high-throughput migration time alignment preprocessing of electrophoretic data retrieved via multiplexed capillary gel electrophoresis with laser-induced fluorescence detection-based glycoprofiling. Electrophoresis 34(16):2311-2315

Bielser JM, Kraus L, Burgos-Morales O, Broly H, Souquet J (2020) Reduction of medium consumption in perfusion mammalian cell cultures using a perfusion rate equivalent concentrated nutrient feed. Biotechnol Prog 36(5):1-8

Bondt A, Rombouts Y, Selman MHJ, Hensbergen PJ, Reiding KR, Hazes JMW et al (2014) Immunoglobulin $\mathrm{G}$ (IgG) fab glycosylation analysis using a new mass spectrometric highthroughput profiling method reveals pregnancy-associated changes. Mol Cell Proteomics 13 (11):3029-3039

Borza B, Szigeti M, Szekrenyes A, Hajba L, Guttman A (2018) Glycosimilarity assessment of biotherapeutics 1: quantitative comparison of the $\mathrm{N}$-glycosylation of the innovator and a biosimilar version of etanercept. J Pharm Biomed Anal 153:182-185. https://doi.org/10.1016/ j.jpba.2018.02.021

Briggs JB, Keck RG, Ma S, Lau W, Jones AJS (2009) An analytical system for the characterization of highly heterogeneous mixtures of N-linked oligosaccharides. Anal Biochem 389(1):40-51

Bunz S-C, Cutillo F, Neusüß C (2013a) Analysis of native and APTS-labeled N-glycans by capillary electrophoresis/time-of-flight mass spectrometry. Anal Bioanal Chem 405 (25):8277-8284

Bunz SC, Rapp E, Neusüss C (2013b) Capillary electrophoresis/mass spectrometry of APTSlabeled glycans for the identification of unknown glycan species in capillary electrophoresis/ laser- induced fluorescence systems. Anal Chem 85(21):10218-10224

Callewaert N, Geysens S, Molemans F, Contreras R (2001) Ultrasensitive profiling and sequencing of N-linked oligosaccharides using standard DNA-sequencing equipment. Glycobiology 11 (4):275-281

Campa C, Rossi M (2008) Capillary electrophoresis of neutral carbohydrates: mono-, oligosaccharides, glycosides. Methods Mol Biol 384:247-305

Chen J, Fang M, Chen X, Yi C, Ji J, Cheng C et al (2017) N-glycosylation of serum proteins for the assessment of patients with IgD multiple myeloma. BMC Cancer 17(1):881. Available from: https://bmccancer.biomedcentral.com/articles/10.1186/s12885-017-3891-3

Chinuki Y, Morita E (2019) Alpha-Gal-containing biologics and anaphylaxis. Allergol Int 68 (3):296-300. https://doi.org/10.1016/j.alit.2019.04.001

Chung CH, Mirakhur B, Chan E, Le Q-T, Berlin J, Morse M et al (2008) Cetuximab-induced anaphylaxis and IgE specific for galactose- $\alpha$-1,3-galactose. N Engl J Med 358(11):1109-1117

Clerc F, Reiding KR, Jansen BC, Kammeijer GSM, Bondt A, Wuhrer M (2016) Human plasma protein N-glycosylation. Glycoconj J 33(3):309-343

Collins FS, Lander ES, Rogers J et al (2004) International human genome sequencing consortium, finishing the euchromatic sequence of the human genome. Nature 431(7011):931-945 
Coppa GV, Gabrielli O, Pierani P, Catassi C, Carlucci A, Giorgi PL (1993) Changes in carbohydrate composition in human milk over 4 months of lactation. Pediatrics 91(3):637-641. Available from: http://pediatrics.aappublications.org/content/91/3/637.abstract

Croset A, Delafosse L, Gaudry JP, Arod C, Glez L, Losberger C et al (2012) Differences in the glycosylation of recombinant proteins expressed in HEK and CHO cells. J Biotechnol 161 (3):336-348. https://doi.org/10.1016/j.jbiotec.2012.06.038

Dalziel M, McFarlane I, Axford JS (1999) Lectin analysis of human immunoglobulin G N-glycan sialylation. Glycoconj J 16(12):801-807

De Leoz MLA, Duewer DL, Fung A, Liu L, Yau HK, Potter O et al (2020) NIST interlaboratory study on glycosylation analysis of monoclonal antibodies: comparison of results from diverse analytical methods. Mol Cell Proteomics 19(1):11-30

Donczo B, Szarka M, Tovari J, Ostoros G, Csanky E, Guttman A (2017) Molecular glycopathology by capillary electrophoresis: analysis of the $\mathrm{N}$-glycome of formalin-fixed paraffin-embedded mouse tissue samples. Electrophoresis 38(12):1602-1608

Dotz V, Haselberg R, Shubhakar A, Kozak RP, Falck D, Rombouts Y et al (2015) Mass spectrometry for glycosylation analysis of biopharmaceuticals. TrAC Trends Anal Chem 73:1-9

Eussen SRBM, Mank M, Kottler R et al (2021) Presence and levels of galactosyllactoses and other oligosaccharides in human milk and their variation during lactation and according to maternal phenotype. Nutrients 13:2324. https://doi.org/10.3390/nu13072324

Evangelista RA, Liu M-S, Chen F-TA (1995) Characterization of 9-aminopyrene-1,4,6-trisulfonate derivatized sugars by capillary electrophoresis with laser-induced fluorescence detection. Anal Chem 67(13):2239-2245

Feng H, Li P, Rui G, Stray J, Khan S, Chen S-M et al (2017) Multiplexing N-glycan analysis by DNA analyzer. Electrophoresis 38(13-14):1788-1799

Gattu S, Crihfield CL, Holland LA (2017) Microscale measurements of michaelis-menten constants of neuraminidase with nanogel capillary electrophoresis for the determination of the sialic acid linkage. Anal Chem 89(1):929-936

Gebri E, Kovács Z, Mészáros B, Tóth F, Simon Á, Jankovics H et al (2020) N-glycosylation alteration of serum and salivary immunoglobulin A is a possible biomarker in oral mucositis. $\mathrm{J}$ Clin Med 9(6): 1747

Gennaro LA, Salas-Solano O (2008) On-line CE-LIF-MS technology for the direct characterization of N-linked glycans from therapeutic antibodies. Anal Chem 80(10):3838-3845

glyXera (2020) glyXprep ${ }^{\mathrm{TM}}$ kit for N-glycan analysis [cited 2020 Mar 30]. Available from: https:// www.glyxera.com/product/glyxprep/

glyXera (2021) glyXtoolCE. [cited 2021 Mar 30]. Available from: https://www.glyxera.com/ product/glyxtool-ce/

GU database

Guttman A (1996) High-resolution carbohydrate profiling by capillary gel electrophoresis. Nature 380(6573):461-462

Guttman A (1997) Multistructure sequencing of N-linked fetuin glycans by capillary gel electrophosesis and enzyme matrix digestion. Electrophoresis 18(7):1136-1141

Guttman A, Herrick S (1996) Effect of the quantity and linkage position of mannose $(\alpha 1,2)$ residues in capillary gel electrophoresis of high-mannose-type oligosaccharides. Anal Biochem 235 (2):236-239

Guttman A, Ulfelder KW (1997) Exoglycosidase matrix-mediated sequencing of a complex glycan pool by capillary electrophoresis. J Chromatogr A 781(1-2):547-554

Guttman A, Cooke N, Starr CM (1994) Capillary electrophoresis separation of oligosaccharides: I. Effect of operational variables. Electrophoresis 15(12):1518-1522

Guttman A, Chen F-TA, Evangelista RA (1996a) Separation of 1-aminopyrene-3,6,8-trisulfonatelabeled asparagine-linked fetuin glycans by capillary gel electrophoresis. Electrophoresis 17 (2):412-417 
Guttman A, Chen F-TA, Evangelista RA, Cooke N (1996b) High-resolution capillary gel electrophoresis of reducing oligosaccharides labeled with 1-aminopyrene-3,6,8-trisulfonate. Anal Biochem 233(2):234-242

Guttman M, Váradi C, Lee KK, Guttman A (2015) Comparative glycoprofiling of HIV gp120 immunogens by capillary electrophoresis and MALDI mass spectrometry. Electrophoresis 36 (11-12):1305-1313

Hennig R, Borowiak M, Ruhaak LR, Wuhrer M, Rapp E (2011a) High-throughput CGE-LIF based analysis of APTS-labeled N-glycans, utilizing a multiplex capillary DNA sequencer. Glycoconj J 28(5):331

Hennig R, Reichl U, Rapp E (2011b) A software tool for automated high-throughput processing of CGE-LIF based glycoanalysis data, generated by a multiplexing capillary DNA sequencer. Glycoconj J 28(5):331

Hennig R, Rapp E, Kottler R, Cajic S, Borowiak M, Reichl U (2015) N-Glycosylation fingerprinting of viral glycoproteins by xCGE-LIF. Methods Mol Biol 1331:123-143

Hennig R, Cajic S, Borowiak M, Hoffmann M, Kottler R, Reichl U et al (2016) Towards personalized diagnostics via longitudinal study of the human plasma $\mathrm{N}$-glycome. Biochim Biophys Acta Gen Subj 1860(8):1728-1738

Hjertén S (1967) Free zone electrophoresis. Chromatogr Rev 9(2):122-219

Holland LA, Chetwyn NP, Perkins MD, Lunte SM (1997) Capillary electrophoresis in pharmaceutical analysis. Pharm Res 14(4):372-387

Holland LA, Gattu S, Crihfield CL, Bwanali L (2017) Capillary electrophoresis with stationary nanogel zones of galactosidase and Erythrina cristagalli lectin for the determination of $\beta(1-3)-$ linked galactose in glycans. J Chromatogr A 1523:90-96

Houeix B, Cairns MT (2019) Engineering of CHO cells for the production of vertebrate recombinant sialyltransferases. Peer J 7:e5788. https://doi.org/10.7717/peerj.5788

Huang C, Liu Y, Wu H, Sun D, Li Y (2017) Characterization of IgG glycosylation in rheumatoid arthritis patients by MALDI-TOF-MSn and capillary electrophoresis. Anal Bioanal Chem 409 (15):3731-3739

Huffman JE, Pučić-Baković M, Klarić L, Hennig R, Selman MHJ, Vučković F et al (2014) Comparative performance of four methods for high-throughput glycosylation analysis of immunoglobulin G in genetic and epidemiological research. Mol Cell Proteomics 13(6):1598-1610

Huhn C, Ruhaak LR, Mannhardt J, Wuhrer M, Neusüß C, Deelder AM et al (2012) Alignment of laser-induced fluorescence and mass spectrometric detection traces using electrophoretic mobility scaling in CE-LIF-MS of labeled N-glycans. Electrophoresis 33(4):563-566

Jacob GS, Scudder P (1994) Glycosidases in structural analysis. Methods Enzymol 230:280-299

Janin-Bussat M-C, Tonini L, Huillet C, Colas O, Klinguer-Hamour C, Corvaïa N et al (2013) Cetuximab Fab and Fe N-glycan fast characterization using IdeS digestion and liquid chromatography coupled to electrospray ionization mass spectrometry. In: Beck A (ed) Glycosylation engineering of biopharmaceuticals: methods and protocols. Humana Press, Totowa, NJ, pp 93-113. https://doi.org/10.1007/978-1-62703-327-5_7

Jarvas G, Szigeti M, Guttman A (2015) GUcal: an integrated application for capillary electrophoresis based glycan analysis. Electrophoresis 36(24):3094-3096

Jarvas G, Szigeti M, Chapman J, Guttman A (2016) Triple-internal standard based glycan structural assignment method for capillary electrophoresis analysis of carbohydrates. Anal Chem 88 (23): 11364-11367

Jarvas G, Szigeti M, Guttman A (2018) Structural identification of N-linked carbohydrates using the GUcal application: a tutorial. J Proteome 171:107-115

Jayo RG, Li J, Chen DDY (2012) Capillary electrophoresis mass spectrometry for the characterization of O-Acetylated N-glycans from fish serum. Anal Chem 84(20):8756-8762

Jayo RG, Thaysen-Andersen M, Lindenburg PW, Haselberg R, Hankemeier T, Ramautar R et al (2014) Simple capillary electrophoresis-mass spectrometry method for complex glycan analysis using a flow-through microvial interface. Anal Chem 86(13):6479-6486 
Jorgenson JW, DeArman Lukacs K (1981) Zone electrophoresis in open-tubular glass capillaries: preliminary data on performance. J High Resolut Chromatogr 4(5):230-231

Jorgenson JW, Lukacs KD (1981a) Free-zone electrophoresis in glass capillaries. Clin Chem 27 (9):1551-1553

Jorgenson JW, Lukacs KD (1981b) Zone electrophoresis in open-tubular glass capillaries. Anal Chem 53(8):1298-1302

Kamerling JP, Gerwig GJ (2007) Strategies for the structural analysis of carbohydrates. Compr Glycosci From Chem to Syst Biol 2-4:1-68

Kanda Y, Yamada T, Mori K, Okazaki A, Inoue M, Kitajima-Miyama K et al (2007) Comparison of biological activity among nonfucosylated therapeutic IgG1 antibodies with three different $\mathrm{N}$-linked Fc oligosaccharides: the high-mannose, hybrid, and complex types. Glycobiology 17(1):104-118

Kinoshita N, Ohno M, Nishiura T, Fujii S, Nishikawa A, Kawakami Y et al (1991) Glycosylation at the Fab portion of myeloma immunoglobulin $\mathrm{G}$ and increased fucosylated biantennary sugar chains: structural analysis by high-performance liquid chromatography and antibody-lectin enzyme immunoassay using Lens culinaris agglutinin. Cancer Res 51(21):5888-5892

Kobata A (2013) Exo- and endoglycosidases revisited. Proc Jpn Acad Ser B Phys Biol Sci 89 (3):97-117

Kobata A, Takasaki S (1992) Structural characterization of oligosaccharides from glycoproteins. 4A Glycosidase treatment and other methods, including methylation analysis. In: Glycobiology: a practical approach. IRL Press, Oxford, pp 165-185

Konze SA, Cajic S, Oberbeck A, Hennig R, Pich A, Rapp E et al (2017) Quantitative assessment of sialo-glycoproteins and $\mathrm{N}$-glycans during cardiomyogenic differentiation of human induced pluripotent stem cells. ChemBioChem 18(13):1317-1331

Kottler R, Mank M, Hennig R, Müller-Werner B, Stahl B, Reichl U et al (2013) Development of a high-throughput glycoanalysis method for the characterization of oligosaccharides in human milk utilizing multiplexed capillary gel electrophoresis with laser-induced fluorescence detection. Electrophoresis 34(16):2323-2336

LabChip Microfluidics (2018) Rapid analysis of N-glycans on theLabChip GXII touch microchipCE platform [cited 2018 May 22]. Available from: https://www.perkinelmer.com/lab-solutions/ resources/docs/APP_Rapid_Analysis_N-Glycans_on_LabChip_GXII_Touch.pdf

Lageveen-Kammeijer GSM, de Haan N, Mohaupt P, Wagt S, Filius M, Nouta J et al (2019) Highly sensitive CE-ESI-MS analysis of N-glycans from complex biological samples. Nat Commun [cited 2019 May 20] 10(1):2137. Available from: http://www.nature.com/articles/s41467-01909910-7

Laroy W, Contreras R, Callewaert N (2006) Glycome mapping on DNA sequencing equipment. Nat Protoc 1(1):397-405

Lauc G, Huffman JE, Pučić M, Zgaga L, Adamczyk B, Mužinić A et al (2013) Loci associated with $\mathrm{N}$-glycosylation of human immunoglobulin G show pleiotropy with autoimmune diseases and haematological cancers. PLoS Genet 9(1):e1003225

Lebede M, Di Marco F, Esser-Skala W, Hennig R, Wohlschlager T, Huber CG (2021) Exploring the chemical space of protein glycosylation in non-covalent protein complexes: an expedition along different struc-tural levels of human chorionic gonadotropin employing mass spectrometry. $\mathbf{J}$ Am Chem Soc. https://doi.org/10.1021/acs.analchem.1c02199

Lindenburg PW, Haselberg R, Rozing G, Ramautar R (2015) Developments in interfacing designs for CE-MS: towards enabling tools for proteomics and metabolomics. Chromatographia 78 (5-6):367-377

Liu XE, Desmyter L, Gao CF, Laroy W, Dewaele S, Vanhooren V et al (2007) N-glycomic changes in hepatocellular carcinoma patients with liver cirrhosis induced by hepatitis B virus. Hepatology 46(5):1426-1435

Lu G, Crih CL, Gattu S, Veltri LM, Holland LA, Bennett CE et al (2018) Capillary electrophoresis separations of glycans. Chem Rev 118(17):7867-7885. https://doi.org/10.1021/acs.chemrev. $7 \mathrm{~b} 00669$ 
Ludger (2018) Glycan labeling kits [cited 2018 May 16]. Available from: https://www.ludger.com/ products/glycan_labeling_kits.php

Luo R, Archer-Hartmann SA, Holland LA (2010) Transformable capillary electrophoresis for oligosaccharide separations using phospholipid additives. Anal Chem 82(4):1228-1233

Ma S, Nashabeh W (1999) Carbohydrate analysis of a chimeric recombinant monoclonal antibody by capillary electrophoresis with laser-induced fluorescence detection. Anal Chem 71 (22):5185-5192

Mahan AE, Tedesco J, Dionne K, Baruah K, Cheng HD, De Jager PL et al (2015) A method for high-throughput, sensitive analysis of IgG Fc and Fab glycosylation by capillary electrophoresis. J Immunol Methods 417:34-44. https://doi.org/10.1016/j.jim.2014.12.004

Mattu TS, Pleass RJ, Willis AC, Kilian M, Wormald MR, Lellouch AC et al (1998) The glycosylation and structure of human serum IgA1, Fab, and Fc regions and the role of N-glycosylation on Fc $\alpha$ receptor interactions. J Biol Chem 273(4):2260-2272

Maverakis E, Kim K, Shimoda M, Gershwin ME, Patel F, Wilken R et al (2015) Glycans in the immune system and the altered glycan theory of autoimmunity: a critical review. J Autoimmun 57(January):1-13. https://doi.org/10.1016/j.jaut.2014.12.002

Maxwell EJ, Chen DDY (2008) Twenty years of interface development for capillary electrophoresis-electrospray ionization-mass spectrometry. Anal Chim Acta 627(1):25-33

Mcleod B (2013) Characterization of glycans from erbitux ${ }^{\circledR}$, Rituxan ${ }^{\circledR}$ and Enbrel ${ }^{\circledR}$ using PNGase F (glycerol-free), recombinant. Glycobiol Protein Tools-New Engl Biolabs:2-5. Available from: https://www.neb.com/-/media/catalog/application-notes/characterization-of-glycansfrom-erbitux-rituxan-and-enbrel-using-pngase-f-glycerol-free-recombinant.pdf

Mechref Y (2013) Glycomic profiling through capillary electrophoresis and microchip capillary electrophoresis. In: Capillary electrophoresis and microchip capillary electrophoresis. Wiley, Hoboken, NJ, pp 367-383

Mechref Y, Novotny MV (2009) Glycomic analysis by capillary electrophoresis-mass spectrometry. Mass Spectrom Rev 28(2):207-222

Mechref Y, Muzikar J, Novotny MV (2005) Comprehensive assessment of N-glycans derived from a murine monoclonal antibody: a case for multimethodological approach. Electrophoresis 26 (10):2034-2046

Meininger M, Stepath M, Hennig R, Cajic S, Rapp E, Rotering H et al (2016) Sialic acid-specific affinity chromatography for the separation of erythropoietin glycoforms using serotonin as a ligand. J Chromatogr B 1012-1013:193-203

Meszaros B, Kovacs Z, Gebri E, Jankovics H, Vonderviszt F, Kiss A et al (2020) N-glycomic analysis of $\mathrm{Z}(\operatorname{IgA} 1)$ partitioned serum and salivary immunoglobulin A by capillary electrophoresis. Curr Mol Med 20:781-788. Available from: http://www.eurekaselect.com/node/180847/ article

Mitra I, Zhuang Z, Zhang Y, Yu C-Y, Hammoud ZT, Tang H et al (2012) N-glycan profiling by microchip electrophoresis to differentiate disease states related to esophageal adenocarcinoma. Anal Chem 84(8):3621-3627

Mitra I, Alley WR, Goetz JA, Vasseur JA, Novotny MV, Jacobson SC et al (2013) Comparative profiling of $\mathrm{N}$-glycans isolated from serum samples of ovarian cancer patients and analyzed by microchip electrophoresis. J Proteome Res 12(10):4490-4496

Mitra I, Snyder CM, Zhou X, Campos MI, Alley WR, Novotny MV et al (2016) Structural characterization of serum N-glycans by methylamidation, fluorescent labeling, and analysis by microchip electrophoresis. Anal Chem 88(18):8965-8971

Mittermayr S, Guttman A (2012) Influence of molecular configuration and conformation on the electromigration of oligosaccharides in narrow bore capillaries. Electrophoresis 33 (6):1000-1007

Mittermayr S, Bones J, Guttman A (2013) Unraveling the glyco-puzzle: glycan structure identification by capillary electrophoresis. Anal Chem 85(9):4228-4238

Muñoz RI, Kähne T, Herrera H, Rodríguez S, Guerra MM, Vío K et al (2019) The subcommissural organ and the Reissner fiber: old friends revisited. Cell Tissue Res 375(2):507-529 
Nakano M, Kakehi K, Taniguchi N, Kondo A (2011) Capillary electrophoresis and capillary electrophoresis-mass spectrometry for structural analysis of N-glycans derived from glycoproteins. In: Capillary electrophoresis of carbohydrates. Humana Press, Totowa, NJ, pp 205-235

Novak J, Moldoveanu Z, Renfrow MB, Yanagihara T, Suzuki H, Raska M et al (2007) IgA nephropathy and henoch-schoenlein purpura nephritis: aberrant glycosylation of IgA1, formation of IgA1-containing immune complexes, and activation of mesangial cells. Contrib Nephrol 157:134-138

O'Flaherty R, Harbison AM, Hanley PJ, Taron CH, Fadda E, Rudd PM (2017) Aminoquinoline fluorescent labels obstruct efficient removal of $\mathrm{N}$-glycan core $\alpha(1-6)$ fucose by bovine kidney $\alpha$ L -fucosidase (BKF). J Proteome Res 16(11):4237-4243

Olivares JA, Nguyen NT, Yonker CR, Smith RD (1987) On-line mass spectrometric detection for capillary zone electrophoresis. Anal Chem 59(8):1230-1232

Parker BL, Thaysen-Andersen M, Solis N, Scott NE, Larsen MR, Graham ME et al (2013) Sitespecific glycan-peptide analysis for determination of N-glycoproteome heterogeneity. J Proteome Res 12(12):5791-5800

Patenaude AM, Erhardt J, Hennig R, Rapp E, Lauc G, Pezer M (2020) N-glycosylation analysis of mouse immunoglobulin $\mathrm{G}$ isolated from dried blood spots. Electrophoresis:1-11. https://doi. org/10.1002/elps.202000249

PerkinElmer (2018) Glycan profiling assay release and labeling kit [cited 2018 May 22]. Available from: http://www.perkinelmer.de/product/glycan-release-and-labeling-kit-760523

Pioch M, Bunz SC, Neusüß C (2012) Capillary electrophoresis/mass spectrometry relevant to pharmaceutical and biotechnological applications. Electrophoresis 33(11):1517-1530

Pioch M, Hoffmann M, Pralow A, Reichl U, Rapp E (2018) GlyXtoolMS: an open-source pipeline for semiautomated analysis of glycopeptide mass spectrometry data. Anal Chem 90 (20):11908-11916

Pralow A, Hoffmann M, Nguyen-Khuong T, Pioch M, Hennig R, Genzel Y, Rapp E, Reichl U (2021) Comprehensive N-glycosylation analysis of the influenza A virus proteins HA and NA from adherent and suspension MDCK cells. FEBS J. https://doi.org/10.1111/febs.15787

Primack J, Flynn GC, Pan H (2011) A high-throughput microchip-based glycan screening assay for antibody cell culture samples. Electrophoresis 32(10):1129-1132

Prime S, Merry T (1998) Exoglycosidase sequencing of N-linked glycans by the reagent array analysis method (RAAM). Methods Mol Biol 76:53-69

ProZyme (2018) GlykoPrep ${ }^{\circledR}$ rapid N-glycan preparation with APTS (24-ct) [GP24NG-APTS]. ProZyme-product [cited 2018 May 16]. Available from: https://prozyme.com/products/gp24ngapts

Pučić M, Knežević A, Vidič J, Adamczyk B, Novokmet M, Polašek O et al (2011) High throughput isolation and glycosylation analysis of IgG-variability and heritability of the IgG glycome in three isolated human populations. Mol Cell Proteomics 10(10):1-15

Qian J, Liu T, Yang L, Daus A, Crowley R, Zhou Q (2007) Structural characterization of N-linked oligosaccharides on monoclonal antibody cetuximab by the combination of orthogonal matrixassisted laser desorption/ionization hybrid quadrupole-quadrupole time-of-flight tandem mass spectrometry and sequential enzy. Anal Biochem 364(1):8-18

Raju TS, Briggs JB, Borge SM, Jones AJS (2000) Species-specific variation in glycosylation of Igc: evidence for the species-specific sialylation and branch-specific galactosylation and importance for engineering recombinant glycoprotein therapeutics. Glycobiology 10(5):477-486

Reusch D, Haberger M, Kailich T, Heidenreich A-K, Kampe M, Bulau P et al (2014) Highthroughput glycosylation analysis of therapeutic immunoglobulin $\mathrm{G}$ by capillary gel electrophoresis using a DNA analyzer. MAbs 6(1):185-196

Reusch D, Haberger M, Maier B, Maier M, Kloseck R, Zimmermann B et al (2015a) Comparison of methods for the analysis of therapeutic immunoglobulin $\mathrm{G} \mathrm{Fc}$-glycosylation profiles-part 1: separation-based methods. MAbs 7(1):167-179. https://doi.org/10.4161/19420862.2014. 986000 
Reusch D, Haberger M, Falck D, Peter B, Maier B, Gassner J et al (2015b) Comparison of methods for the analysis of therapeutic immunoglobulin $\mathrm{G} \mathrm{Fc}$-glycosylation profiles-part 2: mass spectrometric methods. MAbs 7(4):732-742

Routier FH, Hounsell EF, Rudd PM, Takahashi N, Bond A, Hay FC et al (1998) Quantitation of the oligosaccharides of human serum IgG from patients with rheumatoid arthritis: a critical evaluation of different methods. J Immunol Methods 213(2):113-130

Rudd PM, Dwek RA (1997) Rapid, sensitive sequencing of oligosaccharides from glycoproteins. Curr Opin Biotechnol 8(4):488-497

Ruess FF (1809) Notice sur un nouvel effet de l'électricité galvanique. In: Mémoires de la Société Impériale des Naturalistes de l'Université Impérial e de Moscou. Impr. de l'Université impériale, Moscou, pp 327-336

Ruhaak LR, Huhn C, Waterreus W-J, de Boer AR, Neusüss C, Hokke CH et al (2008) Hydrophilic interaction chromatography-based high-throughput sample preparation method for $\mathrm{N}$-glycan analysis from total human plasma glycoproteins. Anal Chem 80(15):6119-6126

Ruhaak LR, Zauner G, Huhn C, Bruggink C, Deelder AM, Wuhrer M (2010a) Glycan labeling strategies and their use in identification and quantification. Anal Bioanal Chem 397 (8):3457-3481

Ruhaak LR, Hennig R, Huhn C, Borowiak M, Dolhain RJEM, Deelder AM et al (2010b) Optimized workflow for preparation of APTS-labeled N-glycans allowing high-throughput analysis of human plasma glycomes using 48-channel multiplexed CGE-LIF. J Proteome Res 9 (12):6655-6664

Ruhaak LR, Steenvoorden E, Koeleman CAM, Deelder AM, Wuhrer M (2010c) 2-Picoline-borane: a non-toxic reducing agent for oligosaccharide labeling by reductive amination. Proteomics 10 (12):2330-2336

Ruhaak LR, Huhn C, Koeleman CAM, Deelder AM, Wuhrer M (2012) Robust and high-throughput sample preparation for (semi-)quantitative analysis of $\mathrm{N}$-glycosylation profiles from plasma samples. Methods Mol Biol 893:371-385

Russell AC, Šimurina M, Garcia MT, Novokmet M, Wang Y, Rudan I et al (2017) The $\mathrm{N}$-glycosylation of immunoglobulin $\mathrm{G}$ as a novel biomarker of Parkinson's disease. Glycobiology 27(5):501-510

Saraswathy N, Ramalingam P (2011) DNA sequencing methods, chapter5. In: Concepts and techniques in genomics and proteomics. Woodhead, Oxford, $\mathrm{p} 57$

Sarkozy D, Borza B, Domokos A, Varadi E, Szigeti M, Meszaros-Matwiejuk A et al (2021) Ultrafast high-resolution analysis of human milk oligosaccharides by multicapillary gel electrophoresis. Food Chem 341:128200. https://doi.org/10.1016/j.foodchem.2020.128200

Schaffert A, Hanić M, Novokmet M, Zaytseva O, Krištić J, Lux A et al (2020) Minimal B cell extrinsic IgG glycan modifications of pro- and anti-inflammatory IgG preparations in vivosupplementary material. Front Immunol 10:3024

Schwarzer J, Rapp E, Reichl U (2008) N-glycan analysis by CGE-LIF: profiling influenza A virus hemagglutinin N-glycosylation during vaccine production. Electrophoresis 29(20):4203-4214

Schwedler C, Kaup M, Weiz S, Hoppe M, Braicu EI, Sehouli J et al (2014a) Identification of $34 \mathrm{~N}$-glycan isomers in human serum by capillary electrophoresis coupled with laser-induced fluorescence allows improving glycan biomarker discovery. Anal Bioanal Chem 406 (28):7185-7193

Schwedler C, Kaup M, Petzold D, Hoppe B, Braicu EI, Sehouli J et al (2014b) Sialic acid methylation refines capillary electrophoresis laser-induced fluorescence analyses of immunoglobulin G N-glycans of ovarian cancer patients. Electrophoresis 35(7):1025-1031

SCIEX (2018) Fast glycan analysis and labeling for the PA 800 plus [cited 2018 May 16]. Available from: https://sciex.com/products/consumables-and-standards/fast-glycan-analysis-and-label ing-for-the-pa-800-plus

Shade KTC, Conroy ME, Washburn N, Kitaoka M, Huynh DJ, Laprise E et al (2020) Sialylation of immunoglobulin E is a determinant of allergic pathogenicity. Nature 582(7811):265-270. https://doi.org/10.1038/s41586-020-2311-z 
Simó C, Cifuentes A (2005) Mass spectrometry detection in capillary electrophoresis. In: Analysis and detection by capillary electrophoresis. Elsevier, Amsterdam, pp 441-517

Smejkal P, Szekrényes Á, Ryvolová M, Foret F, Guttman A, Bek F et al (2010) Chip-based CE for rapid separation of 8-aminopyrene-1,3,6-trisulfonic acid (APTS) derivatized glycans. Electrophoresis 31(22):3783-3786

Smith RD, Olivares JA, Nguyen NT, Udseth HR (1988a) Capillary zone electrophoresis-mass spectrometry using an electrospray ionization interface. Anal Chem 60(5):436-441

Smith RD, Barinaga CJ, Udseth HR (1988b) Improved electrospray ionization interface for capillary zone electrophoresis-mass spectrometry. Anal Chem 60(18):1948-1952

Snyder CM, Alley WR, Campos MI, Svoboda M, Goetz JA, Vasseur JA et al (2016) Complementary glycomic analyses of sera derived from colorectal cancer patients by MALDI-TOF-MS and microchip electrophoresis. Anal Chem 88(19):9597-9605

Snyder CM, Zhou X, Karty JA, Fonslow BR, Novotny MV, Jacobson SC (2017) Capillary electrophoresis-mass spectrometry for direct structural identification of serum $\mathrm{N}$-glycans. J Chromatogr A 1523:127-139

Stadlmann J, Pabst M, Kolarich D, Kunert R, Altmann F (2008) Analysis of immunoglobulin glycosylation by LC-ESI-MS of glycopeptides and oligosaccharides. Proteomics 8 (14):2858-2871

Suzuki H, Muller O, Guttman A, Karger BL (1997) Analysis of 1-aminopyrene 3,6,8-trisulfonatederivatized oligosaccharides by capillary electrophoresis with matrix-assisted laser desorption/ ionization time-of-flight mass spectrometry. Anal Chem 69(22):4554-4559

Szabo Z, Guttman A, Bones J, Shand RL, Meh D, Karger BL (2012) Ultrasensitive capillary electrophoretic analysis of potentially immunogenic carbohydrate residues in biologics: galactose- $\alpha$-1,3-galactose containing oligosaccharides. Mol Pharm 9(6):1612-1619

Szigeti M, Guttman A (2017) Automated N-glycosylation sequencing of biopharmaceuticals by capillary electrophoresis. Sci Rep 7(1):11663

Taniguchi T, Mizuochi T, Kobata A, Beale M, Dwek RA, Rademacher TW (1985) Structures of the sugar chains of rabbit immunoglobulin G: occurrence of asparagine-linked sugar chains in $\mathrm{Fab}$ fragment. Biochemistry 24(20):5551-5557

Teranishi K, Manez R, Awwad M, Cooper DKC (2002) Anti-Galo1-3Gal IgM and IgG antibody levels in sera of humans and old world non-human primates. Xenotransplantation 9(2):148-154

Thaysen-Andersen M, Packer NH (2014) Advances in LC-MS/MS-based glycoproteomics: getting closer to system-wide site-specific mapping of the $\mathrm{N}$ - and O-glycoproteome. Biochim Biophys Acta Proteins Proteomics 1844(9):1437-1452. https://doi.org/10.1016/j.bbapap.2014.05.002

Thermo Fisher Scientific (2018) GlycanAssure APTS Kit [cited 2018 May 16]. Available from: http://www.thermofisher.com/order/catalog/product/A28676

Thiesler CT, Cajic S, Hoffmann D, Thiel C, Van Diepen L, Hennig R et al (2016) Glycomic characterization of induced pluripotent stem cells derived from a patient suffering from phosphomannomutase 2 congenital disorder of glycosylation (PMM2-CDG). Mol Cell Proteomics 15(4): 1435-1452

Trbojevic Akmacic I, Ventham NT, Theodoratou E, Vučković F, Kennedy NA, Krištić J et al (2015) Inflammatory bowel disease associates with proinflammatory potential of the immunoglobulin G glycome. Inflamm Bowel Dis 21(6):1237-1247

Uçaktürk E (2012) Analysis of glycoforms on the glycosylation site and the glycans in monoclonal antibody biopharmaceuticals. J Sep Sci 35(3):341-350

Umaña P, Jean-Mairet J, Moudry R, Amstutz H, Bailey JE (1999) Engineered glycoforms of an antineuroblastoma IgG1 with optimized antibody-dependent cellular cytotoxic activity. Nat Biotechnol 17(2):176-180

Vainauskas S, Duke RM, McFarland J, McClung C, Ruse C, Taron CH (2016) Profiling of core fucosylated $\mathrm{N}$-glycans using a novel bacterial lectin that specifically recognizes $\alpha 1,6$ fucosylated chitobiose. Sci Rep 6(September):1-12. https://doi.org/10.1038/srep34195

van de Bovenkamp F (2019) The role of variable domain glycosylation of antibodies in immunity. $\mathrm{PhD}$ Thesis of the University of Amsterdam. Available at: https://dare.uva.nl/search?identifier= af243516-5114-4f95-af99-ba0648757e13 
Van der Linden ECB, Sjoberg ER, Juneja LR, Crocker PR, Varki N, Varki A (2000) Loss of $\mathrm{N}$-glycolylneuraminic acid in human evolution. Implications for sialic acid recognition by siglecs. J Biol Chem 275(12):8633-8640

Vanderschaeghe D, Szekrényes A, Wenz C, Gassmann M, Naik N, Bynum M et al (2010) Highthroughput profiling of the serum N-glycome on capillary electrophoresis microfluidics systems: toward clinical implementation of GlycoHepatoTest. Anal Chem 82(17):7408-7415

Vanderschaeghe D, Guttman A, Callewaert N (2013) High-throughput profiling of the serum $\mathrm{N}$-glycome on capillary electrophoresis microfluidics systems. Methods Mol Biol 919:87-96

Varki A, Cummings RD, Aebi M, Packer NH, Seeberger PH, Esko JD et al (2015) Symbol nomenclature for graphical representations of glycans. Glycobiology 25(12):1323-1324

Wang JR, Gao WN, Grimm R, Jiang S, Liang Y, Ye H et al (2017) A method to identify trace sulfated IgG N-glycans as biomarkers for rheumatoid arthritis. Nat Commun 8(1):1-13. https:// doi.org/10.1038/s41467-017-00662-w

Watson DG (2012) High-performance capillary electrophoresis. In: Pharmaceutical analysis: a textbook for pharmacy students and pharmaceutical chemists. Elsevier Health Sciences, Edinburgh, pp 376-397

Weiz S, Wieczorek M, Schwedler C, Kaup M, Braicu EI, Sehouli J et al (2016) Acute-phase glycoprotein $\mathrm{N}$-glycome of ovarian cancer patients analyzed by CE-LIF. Electrophoresis 37 (11):1461-1467

Yagi Y, Yamamoto S, Kakehi K, Hayakawa T, Ohyama Y, Suzuki S (2011) Application of partialfilling capillary electrophoresis using lectins and glycosidases for the characterization of oligosaccharides in a therapeutic antibody. Electrophoresis 32(21):2979-2985

Yagi Y, Kakehi K, Hayakawa T, Ohyama Y, Suzuki S (2012) Specific detection of $\mathrm{N}$-glycolylneuraminic acid and Gal $1-3 \mathrm{Gal}$ epitopes of therapeutic antibodies by partial-filling capillary electrophoresis. Anal Biochem 431(2):120-126

Yamagami M, Matsui Y, Hayakawa T, Yamamoto S, Kinoshita M, Suzuki S (2017) Plug-plug kinetic capillary electrophoresis for in-capillary exoglycosidase digestion as a profiling tool for the analysis of glycoprotein glycans. J Chromatogr A 1496:157-162

Yamane-Ohnuki N, Kinoshita S, Inoue-Urakubo M, Kusunoki M, Iida S, Nakano R et al (2004) Establishment of FUT8 knockout Chinese hamster ovary cells: an ideal host cell line for producing completely defucosylated antibodies with enhanced antibody-dependent cellular cytotoxicity. Biotechnol Bioeng 87(5):614-622

Yang Y, Franc V, Heck AJR (2017) Glycoproteomics: a balance between high-throughput and in-depth analysis. Trends Biotechnol 35(7):598-609. https://doi.org/10.1016/j.tibtech.2017.04. 010

Yu T, Guo C, Wang J, Hao P, Sui S, Chen X et al (2011) Comprehensive characterization of the site-specific N-glycosylation of wild-type and recombinant human lactoferrin expressed in the milk of transgenic cloned cattle. Glycobiology 21(2):206-224

Zhang W, Hankemeier T, Ramautar R (2017) Next-generation capillary electrophoresis-mass spectrometry approaches in metabolomics. Curr Opin Biotechnol 43:1-7

Zhao Y-P, Xu X-Y, Fang M, Wang H, You Q, Yi C-H et al (2014) Decreased core-fucosylation contributes to malignancy in gastric cancer. Pizzo S V., editor. PLoS One 9(4):e94536

Zhong X, Zhang Z, Jiang S, Li L (2014) Recent advances in coupling capillary electrophoresisbased separation techniques to ESI and MALDI-MS. Electrophoresis 35(9):1214-1225

Zhuang Z, Starkey JA, Mechref Y, Novotny MV, Jacobson SC (2007) Electrophoretic analysis of $\mathrm{N}$-glycans on microfluidic devices. Anal Chem 79(18):7170-7175

Zhuang Z, Mitra I, Hussein A, Novotny MV, Mechref Y, Jacobson SC (2011) Microchip electrophoresis of $\mathrm{N}$-glycans on serpentine separation channels with asymmetrically tapered turns. Electrophoresis 32(2):246-253 
Open Access This chapter is licensed under the terms of the Creative Commons Attribution 4.0 International License (http://creativecommons.org/licenses/by/4.0/), which permits use, sharing, adaptation, distribution and reproduction in any medium or format, as long as you give appropriate credit to the original author(s) and the source, provide a link to the Creative Commons license and indicate if changes were made.

The images or other third party material in this chapter are included in the chapter's Creative Commons license, unless indicated otherwise in a credit line to the material. If material is not included in the chapter's Creative Commons license and your intended use is not permitted by statutory regulation or exceeds the permitted use, you will need to obtain permission directly from the copyright holder. 